Discussion Paper No. 13-071

\title{
Asset Pricing without Garbage
}

Tim A. Kroencke

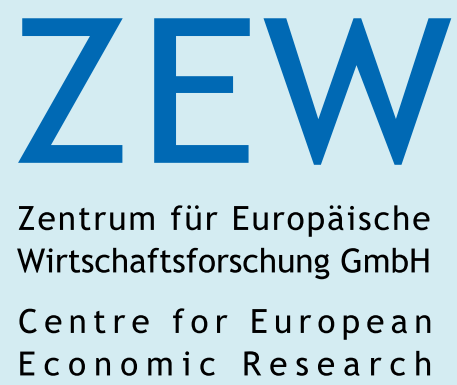




\title{
Discussion Paper No. 13-071 \\ Asset Pricing without Garbage
}

\author{
Tim A. Kroencke
}

Download this ZEW Discussion Paper from our ftp server:

http://ftp.zew.de/pub/zew-docs/dp/dp13071.pdf

Die Discussion Papers dienen einer möglichst schnellen Verbreitung von neueren Forschungsarbeiten des ZEW. Die Beiträge liegen in alleiniger Verantwortung der Autoren und stellen nicht notwendigerweise die Meinung des ZEW dar.

Discussion Papers are intended to make results of ZEW research promptly available to other economists in order to encourage discussion and suggestions for revisions. The authors are solely responsible for the contents which do not necessarily represent the opinion of the ZEW. 


\section{Non-technical summary}

This paper provides an explanation of why garbage as a measure of consumption implies a several times lower coefficient of relative risk aversion in the consumptionbased asset pricing model than consumption based on the official National Income and Product Accounts (NIPA). Unlike garbage, NIPA consumption is filtered to mitigate measurement error. The paper applies a structural model of the filtering process, which allows to revoke the filter inherent in NIPA consumption. "Unfiltered NIPA consumption" performs as well as garbage in explaining the equity premium and risk-free rate puzzle. Furthermore, the paper documents that two other popular NIPA-based measures, three-year and fourth-quarter NIPA consumption, are related to unfiltered NIPA consumption. Both can be viewed as ad hoc unfilter rules.

\section{Das Wichtigste in Kürze}

Dieses Papier bietet einen Erklärungsansatz dafür, warum Abfall als Konsummaß eine wesentlich geringe relative Risikoaversion im konsumbasierten

Kapitalmarktmodell impliziert als Konsum basierend auf der volkswirtschaftlichen

Gesamtrechnung (VGR). Im Unterschied zu Abfall ist VGR Konsum gefiltert um den Einfluss von Messfehlern zu reduzieren. Das Papier nutzt eiOn strukturelles Modell des Filterprozesses aus, um den Filter in VGR Konsum rückgängig zu machen. "Ungefilterter VGR Konsum" kann ebenso gut wie Abfall die Aktienmarktaufschlagsprämie und risikoloser Zins Rätsel erklären. Des Weiteren wird dokumentiert, dass zwei weitere populäre Konsummaße basierend auf der VGR Konsum, und zwar drei-Jahres Konsum und Konsum im vierten Quartal, verwandt mit ungefiltertem VGR Konsum sind. Beide können als ad-hoc Ansätze zur de-filtrierung angesehen werden. 


\title{
Asset Pricing without Garbage*
}

\author{
Tim A. Kroencke ${ }^{\ddagger}$
}

September 15, 2013

\begin{abstract}
This paper provides an explanation why garbage as a measure of consumption implies a several times lower coefficient of relative risk aversion in the consumption-based asset pricing model than consumption based on the official National Income and Product Accounts (NIPA): Unlike garbage, NIPA consumption is filtered to mitigate measurement error. I apply a structural model of the filtering process, which allows to revoke the filter inherent in NIPA consumption. "Unfiltered NIPA consumption" performs as well as garbage in explaining the equity premium and risk-free rate puzzle. Furthermore, I find that two other popular NIPA-based measures, three-year and fourth-quarter NIPA consumption, are related to unfiltered NIPA consumption. Both can be viewed as ad hoc unfilter rules.
\end{abstract}

\section{JEL-Classification: G12}

Keywords: Consumption-based Asset Pricing, Garbage, Filtering.

*I am grateful to John Cochrane, Jonathan Parker, Stefan Ruenzi, Felix Schindler, Andreas Schrimpf, Erik Theissen and seminar participants at the University of Mannheim, and the ZEW Brownbag for comments and suggestions. I am also indebted to Lena Jaroszek and Frieder Mokinski. I thank Alexi Savov for sharing his data. The latest version of the paper and the unfiltered NIPA consumption series can be downloaded at: https://sites.google.com/site/kroencketim

${ }^{\ddagger}$ ZEW Mannheim and University of Mannheim, Email: tim.kroencke@gmail.com. 


\section{Introduction}

The seminal paper by Savov (2011) finds that the consumption-based asset pricing model (CCAPM) using garbage as a measure of consumption matches the equity premium and risk-free rate with a several times lower coefficient of relative risk aversion than any other consumption measure based on the National Income and Product Accounts (NIPA) provided by the U.S. Bureau of Economic Analysis (BEA). Reported NIPA consumption growth has a lower sample standard deviation, a several times higher autocorrelation, and a significantly lower stock market covariance than garbage growth. A possible explanation for the relative success of garbage is that reported NIPA consumption fails to measure consumption properly (Savov (2011, p. 200)). However, one has to keep in mind that dozens of statisticians make a considerable effort to estimate NIPA consumption as precisely as possible. Thus, it is highly unlikely that NIPA consumption is simply badly measured and that the story ends here.

This paper entertains an alternative explanation. Observable consumption is subject to measurement error, which is uncorrelated to stock market returns. From an asset pricing perspective, observable consumption growth would be eligible to measure consumption risk of stock returns, i.e. produces unbiased estimates of consumption covariances. However, NIPA statisticians do not attempt to provide a consumption series to measure stock market consumption risk. The goal they pursue is to estimate the level of consumption as precisely as possible. As a result, they optimally filter observable consumption to generate their series of NIPA consumption. The simpler measure of garbage, on the other hand, is not subject to filtering and accordingly garbage covariances are not "distorted" from filtering. Moreover, filtering is intensified by the well-known bias stemming from time aggregation. Reported consumption is an estimate of consumption flow during a specific period, however, the CCAPM relates asset returns to consumption at one specific point in time (Breeden, Gibbons, and Litzenberger (1989)). As shown in this paper, filtering intensified by time aggregation is disastrous for the stochastic properties of reported NIPA consumption and generally matches the empirically observed differences to garbage.

I apply a structural model to approximate the filtering process in the consumption parts 
of NIPA. The model allows to revoke the filter inherent in NIPA consumption in a simple closed form. I call the measure emerging from this process "unfiltered NIPA consumption". The hypothesis I can test is that the stochastic properties of unfiltered NIPA consumption are similar to those of garbage and mitigate the equity premium and risk-free rate puzzle in the same way.

I also find evidence that unfiltered NIPA consumption is related to three-year consumption (Parker and Julliard (2005)) and fourth-quarter to fourth-quarter consumption (Jagannathan and Wang (2007)). These other two alternative NIPA-based consumption measures were in previous research shown to be priced in the cross-section of stock returns. In support of my hypothesis, this fact implies that there is valuable information latent in NIPA consumption. A simulation experiment shows that fourth-quarter to fourth-quarter consumption is effective in removing time aggregation. In contrast, the three-year consumption measure is effective in removing filtering. In sum, both can be viewed as simple ad hoc unfilter rules. However, in comparison to the direct unfilter method, both measures are less eligible in removing time aggregation and filtering at the same time. Thus, the paper at hand does also provide a unifying explanation for the success of other recently proposed consumption measures.

In the empirical part of the paper, I investigate how good unfiltered NIPA consumption can explain the equity premium and test if unfiltered NIPA consumption is priced in the crosssection of stock returns. First, I find that unfiltered NIPA consumption is able to explain the equity premium and the risk-free rate with a coefficient of relative risk aversion between 19 and 34 in the post-war period (1950 - 2011), which is close to a coefficient between 15 and 25 implied by garbage. A feature of unfiltered NIPA consumption is a sample covering a longer period. When including the pre-war observations in the sample (1927 - 2011), I find a relative risk aversion as low as 9 for unfiltered NIPA consumption. Importantly, unfiltered NIPA consumption can explain the equity premium and the risk-free rate in joint tests going in hand with low pricing errors (Lettau and Ludvigson (2009)). Second, unfiltered NIPA consumption implies a priced consumption risk premium in the cross-section of the 25 FamaFrench portfolio returns, and gives a cross-sectional fit similar to the NIPA-based alternative consumption measures proposed by Parker and Julliard (2005) and Jagannathan and Wang 
(2007). In the full sample, as well as in the shorter post-war sample, I find a cross-sectional $R^{2}$ exceeding 0.50 going in hand with low average pricing errors for unfiltered NIPA consumption.

The unfilter approach applied in this paper was first introduced by Quan and Quigley (1989) and Geltner $(1989,1993)$ in a different context. Research in real estate finds that appraisal-based real estate indices have a lower standard deviation, a substantially larger autocorrelation, and a lower stock market covariance than market value-based real estate indices. Before the work of Quan, Quigley and Geltner, it was a widely accepted fact that appraisal-based values of real estate are simply prone to measurement error, and thus less reliable than market values. Quan, Quigley and Geltner shifted the focus of the literature on the appraisal process, and documented possible reasons for - and the effects of - filtering on time series of real estate indices. In this paper, I argue that "appraised" consumption is subject to very similar issues, and indeed, there is related research supporting this view.

Virtually every paper on consumption-based asset pricing mentions possible problems related to measurement imperfections of consumption. However, surprisingly little work is devoted to analyzing the influence of the measurement methodology on the properties of reported consumption time series. As a rare exception, Wilcox (1992) and Bell and Wilcox (1993) focus on the retail trade survey, which is the most important ingredient of NIPA nondurable consumption. Wilcox (1992) discusses several sources of measurement errors in the construction of U.S. consumption data induced by the retail trade survey, how these imperfections are treated, and summarizes implications for empirical work. Bell and Wilcox (1993) warn that conclusions "about underlying theoretical parameters may be sensitive to imperfections in the data", and propose empirical adjustments to take this issue into account. ${ }^{1}$

The retail trade survey is an important ingredient of NIPA consumption, however, the consumption estimates are subject to several additional sources and issues as is summarized in the official "NIPA handbook" (BEA (2009)). In brief, the sources of NIPA consumption include the Census Bureau, the Bureau of Labor Statistics, the Energy Information Administration, the Internal Revenue Service, and the U.S. Department of Agriculture. These agencies conduct several surveys which take place at different frequencies. Already at this

\footnotetext{
${ }^{1}$ Gregory and Wirjanto (1993) demonstrate how these imperfections may affect results from empirical tests of the CCAPM.
} 
level, a "variety of methods" is used to extract consumption estimates from these surveys and to mitigate measurement errors. For some items, no data is available at all and a residual method is used, i.e. private consumption is measured as residual to business and government purchases. $^{2}$ Following this, final estimates are benchmarked to more comprehensive but less frequently conducted surveys on an annual and quinquennial basis. Non-benchmark years are treated as indicator series which are used to interpolate and extrapolate expenditure patterns from benchmark years. Bell and Wilcox (1993, p. 264) note that benchmarking involves a filtering of the estimates, and thus, "will affect their autocorrelation properties". 3

The internet appendix to Savov (2011 ) provides a description of how the garbage time series is constructed. Several potential sources of measurement error are described. Importantly, the garbage data are considerably more puristic and do not underlie such a complex procedure as is the case for NIPA consumption.

There is considerably more work focusing on the time aggregation bias. For example, Hall (1988) and Grossman, Melino, and Shiller (1987) propose procedures to account for time aggregation in the estimation method. Ait-Sahalia, Parker, and Yogo (2004) report estimates of the coefficient of relative risk aversion, which are simply corrected for time-aggregation by dividing by two. Also the influential paper by Bansal and Yaron (2004) carefully accounts for time aggregation when the model is calibrated to match empirical moments.

As mentioned before, two recent contributions propose the direct use of alternative NIPAbased consumption measures. Parker and Julliard (2005) argue that ultimate consumption risk can provide a "correct measure of risk under several extant explanations of slow consumption adjustment". As their first example for slow consumption adjustment, Parker and Julliard (2005, p. 186) mention "measurement error in consumption". Jagannathan and Wang (2007) consider that investors are more likely to simultaneously make consumption and investment decisions in the fourth-quarter of each year, when the investors' tax year ends, and that the end-of-year consumption is thus a better measure for asset pricing. How-

\footnotetext{
${ }^{2}$ As Savov (2011) points out, business and government purchases can be subject to interpolation or even judgement in place of data. The exact estimation procedure differs between the components of total consumption (see BEA (2009)).

${ }^{3}$ Indeed, Bell and Wilcox (1993) use data on the retail trade survey before benchmarking. I tried to acquire similar non-benchmarked retail trade data to better pin down the effect of benchmarking on the data. It was not possible for me to obtain non-benchmarked data.
} 
ever, using fourth-quarter to fourth-quarter consumption is a straightforward way to mitigate time aggregation and to bring the data closer to point consumption growth as well (Breeden, Gibbons, and Litzenberger (1989), Savov (2011)).

Breeden, Gibbons, and Litzenberger (1989) discuss the possible influence of interpolation and time aggregation in consumption data. They are particularly concerned that interpolation is "exacerbated" by time aggregation, and conclude that "it is difficult to disentangle the two effects" (Breeden, Gibbons, and Litzenberger (1989, p. 243)). Indeed, to my knowledge, their is so far no paper to cite which tried to disentangle both effects. This paper also covers a first attempt on this issue.

The next section will present a structural model of the filter process inherent in NIPA data. The model allows to revoke the filter inherent in NIPA consumption using a simple formula. Furthermore, a small adjustment is suggested in order to take time aggregation into account. A simulation experiment disentangles the two effects of filtering and time aggregation and provides a comparison of the mechanics of three-year consumption and fourth-quarter to fourth-quarter consumption as ad hoc unfilter rules. Section 3 provides the empirical properties of the alternative consumption measures. I use these observations to calibrate "unfiltered NIPA consumption" to garbage. In a next step, I present estimates on the coefficient of relative risk aversion as well as on the consumption risk premium using cross-sectional regressions. Section 4 concludes.

\section{Filtering and Time Aggregation in Consumption Data}

It is not feasible to model all the different layers in the construction of NIPA consumption exactly. Some of the processes involved are not fully known and the original data is not available. However, a more parsimonious approach in the spirit of the adjustments of Bell and Wilcox (1993) or Hall (1988) is promising. I apply a structural model hoping to account for the most important aspects of filtering in the measurement methodology. The main benefit of this approach is a simple closed form solution for calculating "unfiltered NIPA 
consumption", which is easy to interpret and allows to disentangle additional effects from time aggregation. Whether the structural model is a good approximation of reality is an empirical question which will be addressed in Section 3.

\subsection{Stylized Model}

I assume that the state of "true" $\log$ consumption, $c_{t}=\log \left(C_{t}\right)$ follows a Gaussian random walk (Hall (1978)):

$$
c_{t}=c_{t-1}+\sigma_{\eta} \eta_{t}
$$

where $\eta_{t} \sim N(0,1)$ is economic disturbance. Log growth rates are defined as $\triangle c_{t}$. The true state of consumption is not observable. Instead, the observed time series $y_{t}$ satisfies

$$
y_{t}=c_{t}+\sigma_{\xi} \xi_{t}
$$

where $\xi_{t} \sim N(0,1)$ represents measurement error and is uncorrelated with stock market $\log$ returns $r_{m, t}$. It follows that mismeasurement of consumption does not bias estimates of stock market risk: ${ }^{4}$

$$
\operatorname{cov}\left(\triangle c_{t}, r_{m, t}\right)=\operatorname{cov}\left(\triangle y_{t}, r_{m, t}\right)
$$

Thus, for the purpose of asset pricing, $y_{t}$ is well behaved to measure consumption risk of stock returns. However, the goal of the NIPA statisticians is to measure the level of consumption $c_{t}$ as precisely as possible and not $\operatorname{cov}\left(\triangle c_{t}, r_{m, t}\right)$. I define NIPA consumption $\hat{c}_{t}=E_{t}\left(c_{t}\right)$ as an estimate of $c_{t}$ given the arrival of new information $y_{t}$ in the information set $F_{t}=\left\{y_{1}, \ldots, y_{t}\right\}$. Standard textbooks suggest a recursive projection for this problem with the solution (Ljungqvist and Sargent (2004), Tsay (2005)): ${ }^{5}$

$$
\hat{c}_{t}=\hat{c}_{t-1}+\nu\left(y_{t}-\hat{c}_{t-1}\right)
$$

\footnotetext{
${ }^{4}$ This modeling of measurement error in consumption data is put forth by Parker (2001, p.307).

${ }^{5}$ Which is also known as the Kalman (1960) filter for the local level model in state space analysis.
} 


$$
\nu=\frac{\sigma_{\eta}^{2}}{\sigma_{\xi}^{2}+\sigma_{\eta}^{2}} .
$$

Equation (4) implies that the best estimate of NIPA consumption is the NIPA consumption estimate of the past period plus a weighted surprise. Intuitively, if measurement error is large relative to economic disturbance, $\nu$ will be small, and the expectation on the state of consumption should be only slightly updated. In contrast, if there is no measurement error, it is optimal to adjust the expectation on the state of consumption one for one according to the observed variable. ${ }^{6}$

Equation (4) can be rearranged and expressed in terms of log growth rates:

$$
\Delta \hat{c}_{t}=\nu \Delta y_{t}+(1-\nu) \Delta \hat{c}_{t-1}
$$

The key implication of Equation (6) is that filtering adversely effects estimates of stock market risk, i.e. covariances. Returns are uncorrelated with past consumption in the model. For a large degree of filtering, the parameter $\nu$ will be small, and the stock market covariance based on $\Delta \hat{c}_{t}$ will be only a fraction $\nu$ of the true stock market covariance in Equation (3). However, it is straightforward to recover an estimate for unfiltered NIPA consumption by solving Equation (6) backwards:

$$
\Delta \hat{y}_{t}=\frac{\Delta \hat{c}_{t}-(1-\nu) \Delta \hat{c}_{t-1}}{\nu}
$$

where $\Delta \hat{y}_{t}$ is "unfiltered NIPA consumption" and $\Delta \hat{c}_{t}$ corresponds to NIPA consumption. ${ }^{7}$ In terms of the model, garbage can be thought of as observable consumption growth $\triangle y_{t}$

\footnotetext{
${ }^{6}$ In the data, aggregate NIPA consumption volatility is low, which indicates low aggregate measurement error. However, individual components of consumption (e.g. food, clothing, health care) are considerably more volatile, which indicates high measurement error at this level of the data. A similar pattern can be observed for aggregate garbage and the components of garbage (see Savov (2011)). NIPA consumption is constructed bottom-up, i.e. each individual component of consumption is estimated separately as good as possible and is afterwards summed up to aggregate consumption. As a result, the optimal filter at the individual components will be carried over to aggregate consumption. Thus, even if at the aggregate level measurement error of consumption is low, the degree of filtering can be high since measurement error at the individual consumption component level is high. It is straightforward to incorporate individual consumption components into the model to make this point explicit, without changing the main equations.

${ }^{7}$ This backwards induction was proposed by Geltner (1993) to estimate real estate market indices from appraisal-based real estate indices.
} 
not applying filtering in the first place. It follows that unfiltered NIPA consumption is as informative as garbage when measuring consumption risk of stock market returns.

\subsection{Accounting for Time Aggregation}

Time aggregation is another layer of distortion when measuring consumption data and is more widely covered in the literature (e.g. Breeden, Gibbons, and Litzenberger (1989)) than filtering. The following suggests a simple modification of the unfilter rule in Equation (7) to account for time aggregation.

Consumption is usually measured as the flow of consumption during the interval of a specific period, and not as "spot" consumption at one point in time. However, it is spot consumption which conceptually enters the CCAPM. Working (1960) shows that if a variable follows a random walk, the variance of the growth rate of the time aggregated variable is approximately $2 / 3$ that of the true spot growth rate. Furthermore, the first-order autocorrelation is shifted from zero to $1 / 4$, and, as shown by Taio (1972), the covariance to a second variable (e.g. the stock market) is reduced by $1 / 2 .{ }^{8}$ Using a log-linearized version of the CCAPM, the coefficient of relative risk aversion is a linear function of the stock market covariance with consumption (see e.g. Campbell (2003)), and thus, time aggregation will bias estimates on the coefficient of relative risk aversion upwards by a factor of two (Breeden, Gibbons, and Litzenberger (1989)).

There are at least three ways to take time aggregation into account. The first, and most obvious, is to use December to December (or the fourth-quarter to fourth-quarter) consumption growth to reduce time aggregation in the first place (Breeden, Gibbons, and Litzenberger (1989), Savov (2011)). Unfortunately, this option is not available for consumption data in the pre-war sample, where only annual consumption data is available. Second, a relative risk aversion estimate is simply adjusted by dividing by two, since the measured stock market covariance is only one-half of the true covariance (e.g. Breeden, Gibbons, and Litzenberger (1989), Ait-Sahalia, Parker, and Yogo (2004)). Third, Hall (1988) suggests to account for

\footnotetext{
${ }^{8}$ The approximation is exact for infinitesimal measurement intervals, as shown by Breeden, Gibbons, and Litzenberger (1989). In discrete time, these predictions are quite accurate for annual consumption time aggregated on monthly intervals, as can be inferred from Working (1960).
} 
time aggregation using a simple autoregressive representation as an approximation. ${ }^{9}$ In this spirit, Equation (7) can be applied as:

$$
\Delta c_{t}^{S}=\left[\Delta c_{t}^{T A}-(1-\alpha) \Delta c_{t-1}^{T A}\right] / \alpha
$$

to adjust for time aggregation as well, where $\Delta c_{t}^{S}$ is an estimate of spot consumption and $\Delta c_{t}^{T A}$ is the time aggregated measure. It is easy to show that the parameter $\alpha=.80$ ensures that $\Delta c_{t}^{S}$ has the same standard deviation as spot consumption. ${ }^{10}$ Thus, an unfilter rule accounting for time aggregation and filtering can be set up as:

$$
\Delta \hat{y}_{t}=\left[\Delta \hat{c}_{t}-(1-\phi) \Delta \hat{c}_{t-1}\right] / \phi
$$

where $\phi=\alpha \times \nu$. The time aggregation adjustment improves the stock market covariance of consumption through a larger standard deviation. The effect on the stock market correlation is not clear. To shed light on these effects, the following section examines how accurate the modified unfilter rule actually is.

\subsection{Simulation Experiment}

Intuitively, filtering destroys the correlation of consumption growth with stock returns and drives a wedge between garbage and NIPA consumption. To quantify these effects, I simulate a model economy in which consumption-based asset pricing does work. Time aggregation and filtering are added to true consumption to simulate a NIPA consumption measure. The performance of NIPA consumption, unfiltered NIPA consumption, long-run consumption (Parker and Julliard (2005), denoted P-J), and fourth-quarter to fourth-quarter consumption

\footnotetext{
${ }^{9}$ More specifically, to apply the instrumental variables estimator by Hayashi and Sims (1983), Hall uses a second-order forward autoregressive (un)filter to remove autocorrelation of the time aggregated variables. Grossman, Melino, and Shiller (1987) suggest a maximum likelihood estimation strategy taking time aggregation directly into account.

${ }^{10}$ The value $\alpha=.80$ solves:

$$
\operatorname{Var}\left(\Delta c_{t}^{T A}\right)=\frac{\alpha}{2-\alpha} \operatorname{Var}\left(\Delta c_{t}^{S}\right)=\frac{2}{3} \operatorname{Var}\left(\Delta c_{t}^{S}\right)
$$

where the first equality is implied by Equation (8) and the second equality uses the results in Working (1960) and Breeden, Gibbons, and Litzenberger (1989).
} 
(Jagannathan and Wang (2007), denoted Q4Q4), are compared with each other.

Asset Pricing Economy. The simulation is set up such that the pricing equation of the consumption-based model holds:

$$
E\left[\beta\left(\frac{C_{t+1}}{C_{t}}\right)^{-\gamma} R_{m, t+1}^{e}\right]=0,
$$

where $\beta$ is the subjective discount factor, $\gamma$ is the coefficient of relative risk aversion, and $R_{m}^{e}$ is the simple calculated return of the market portfolio in excess of the risk-free rate (equity premium).

I generate 10,000 time-series of the model and take monthly observations of consumption growth and the equity premium from each run such that I can convert them to 60 annual observations. Simulated true consumption growth is calibrated to match with garbage, i.e. the annual standard deviation is $3 \%$ and the true correlation to the stock market is 0.60 . In line with the model outlined above, measurement error for observable consumption (garbage) does not affect estimates of consumption risk and can be therefore ignored in the simulation. I set the true coefficient of relative risk aversion to 15 . The resulting annual equity premium of this economy is $5.1 \%$ carrying a standard deviation of $20 \%$. In a second step, based on the monthly observations, I calculate a "time aggregated" annual NIPA consumption measure, and a further "time aggregated and filtered" NIPA consumption measure. The value of the filter parameter is set to $\nu=1 / 2 .^{11}$

Finally, I calculate the "unfiltered NIPA consumption" measure, the P-J measure as in Parker and Julliard (2005), and the Q4Q4 measure as in Jagannathan and Wang (2007). For unfiltered NIPA consumption, several parameter values $\phi=\alpha \times \nu$ are applied. Taken from the discussion above, the recommended unfilter parameter is $\phi=.80 \times 1=.80$ when NIPA consumption is only time aggregated, and $\phi=.80 \times 1 / 2=.40$ when NIPA consumption is time aggregated and filtered. I also report results for further parameter values of $\phi$ as a sensitivity check. Further details on the simulation can be found in the Appendix to this paper.

\footnotetext{
${ }^{11}$ I find in Section 3 that a filter parameter $\nu$ of $1 / 2$ is in line with empirical observations.
} 
Results. Table 1 provides characteristics of different consumption measures from simulations of a consumption-based asset pricing economy. From the left to the right, the table reports the properties of true consumption (which is equivalent to observable consumption and garbage), NIPA consumption, and the alternative NIPA-based consumption measures using different unfilter rules. Panel A presents results for when NIPA consumption is only time aggregated and Panel B displays results for when NIPA consumption is time aggregated and filtered. 
Table 1: Alternative Consumption Measures in a Simulated Asset Pricing Economy

The table displays statistics on different consumption growth measures in a consumption-based asset pricing economy, $E\left[\beta\left(C_{t+1} / C_{t}\right)^{-\gamma} R_{m, t+1}^{e}\right]=0$. The economy is set up such that true consumption growth matches the empirical characteristics of garbage, i.e. a standard deviation of $3 \%$ and a correlation with stock returns of 0.60 . The true coefficient of relative risk aversion $(\gamma)$ is 15 which implies an equity premium of $5.1 \%$ (with a standard deviation of 20\%). Displayed statistics are the median of 10,000 simulations of monthly data converted to an annual frequency with 60 observations. The reported coefficient of relative risk aversion (RRA $\gamma$ ) is a GMM estimate based on simulated consumption growth and the equity premium. Panel A shows the effect of time aggregation and Panel B shows the effect of time aggregation and filtering on the properties of consumption as reported in the NIPA. The columns to the right compare three different unfilter rules for the NIPA measure: The first two are three-year consumption growth (P-J) as in Parker and Julliard (2005), and fourth-quarter to fourth-quarter consumption growth (Q4Q4) as in Jagannathan and Wang (2007). The third is the new consumption measure using the direct unfilter method proposed in the text. Further simulation details are provided in the Appendix.

Panel A Time Aggregation

\begin{tabular}{|c|c|c|c|c|c|c|c|}
\hline & \multirow{2}{*}{$\begin{array}{c}\text { Consumption } \\
\text { Growth } \\
\text { ("Garbage") }\end{array}$} & \multirow{2}{*}{$\begin{array}{c}\text { Time } \\
\text { Aggregated } \\
\text { ("NIPA") }\end{array}$} & \multicolumn{5}{|c|}{ Unfiltered NIPA Consumption } \\
\hline & & & P-J & Q4Q4 & $\phi=.80$ & $\phi=.53$ & $\phi=.40$ \\
\hline Mean \% & 1.05 & 1.03 & 2.99 & 1.04 & 1.05 & 1.11 & 1.21 \\
\hline St. dev. $\%$ & 3.01 & 2.45 & 4.79 & 2.90 & 2.99 & 4.64 & 6.40 \\
\hline Autocorr. & -0.02 & 0.22 & 0.72 & 0.02 & 0.05 & -0.17 & -0.24 \\
\hline Corr. $R_{M}^{e}$ & 0.57 & 0.37 & 0.34 & 0.54 & 0.39 & 0.38 & 0.37 \\
\hline Cov. $R_{M}^{e} \times 100$ & 0.36 & 0.19 & 0.35 & 0.33 & 0.24 & 0.37 & 0.49 \\
\hline RRA $\gamma$ & 15.04 & 27.62 & 15.84 & 16.40 & 21.95 & 14.15 & 10.43 \\
\hline
\end{tabular}

Panel B

Time Aggregation and Filtering $(\nu=1 / 2)$

\begin{tabular}{|c|c|c|c|c|c|c|c|}
\hline & \multirow{2}{*}{$\begin{array}{c}\text { Consumption } \\
\text { Growth } \\
\text { ("Garbage") }\end{array}$} & \multirow{2}{*}{$\begin{array}{c}\text { Time Aggr. \& } \\
\text { Filtered } \\
\text { ("NIPA") }\end{array}$} & \multicolumn{5}{|c|}{ Unfiltered NIPA Consumption } \\
\hline & & & P-J & Q4Q4 & $\phi=.80$ & $\phi=.53$ & $\phi=.40$ \\
\hline Mean \% & 1.05 & 1.01 & 2.99 & 1.02 & 1.01 & 1.03 & 1.05 \\
\hline St. dev. $\%$ & 3.01 & 1.54 & 3.77 & 2.21 & 1.72 & 2.33 & 3.03 \\
\hline Autocorr. & -0.02 & 0.61 & 0.84 & 0.00 & 0.49 & 0.25 & 0.14 \\
\hline Corr. $R_{M}^{e}$ & 0.57 & 0.28 & 0.35 & 0.49 & 0.32 & 0.37 & 0.38 \\
\hline Cov. $R_{M}^{e} \times 100$ & 0.36 & 0.09 & 0.27 & 0.23 & 0.12 & 0.18 & 0.24 \\
\hline RRA $\gamma$ & 15.04 & 55.02 & 20.31 & 24.10 & 44.80 & 29.34 & 21.88 \\
\hline
\end{tabular}

In Panel A, the properties of NIPA consumption are reasonably close to theoretical predictions. Standard deviation, first-order autocorrelation, and - most importantly - covariation with the stock market deviate from true consumption as can be expected from timeaggregated data (see Section 2). As a result, a Generalized Method of Moments (GMM) estimate for the coefficient of relative risk aversion based on the moment condition implied 
by Equation (10) appears in the simulation with a value of 27, which is about twice as large as the true coefficient of risk aversion of 15. The P-J and the Q4Q4 measures produce large stock market covariances and thus risk aversion estimates which are close to 15 .

The new method with an unfilter parameter $\phi=.80$ slightly increases stock market correlation compared to NIPA consumption (from 0.37 to 0.39 ) and recovers the true standard deviation of consumption of $3 \%$. As a result, the stock market covariance improves considerably and the GMM estimate of risk aversion is 22 , which lies in the middle of the true value and the NIPA consumption-based estimate. Lower values of $\phi$ raise standard deviation of consumption, but they do not raise stock market correlation. As a result, stock market covariation rises and thus brings down the risk aversion estimate. This finding suggests that the parameter $\phi$ should be carefully calibrated in empirical work. As a practical guide, the choice of $\phi$ can be bound by a plausible standard deviation of observable consumption (e.g. garbage) to avoid arbitrary large covariances.

In Panel $\mathrm{B}$, true consumption is time aggregated and filtered $(\nu=1 / 2)$. The impacts on the stochastic properties of consumption are substantial. The standard deviation of simulated NIPA consumption decreases to $1.5 \%$, autocorrelation increases to 0.61 , and stock market correlation is only 0.28. As a result, a tiny covariance of just 0.09 is left and the GMM estimate of relative risk aversion is 55 , which is more than three times larger than the true value of 15 .

Again, P-J and Q4Q4 turn out to be reasonable unfilter rules. However, there are important differences to mere time aggregation. The P-J measure increases the stock market correlation of NIPA consumption, whereas the stock market correlation decreases in Panel A. The Q4Q4 measure recovers less of the stock market correlation compared to Panel A, and thus, covariation is relatively low. Overall, Q4Q4 becomes less effective in recovering true consumption when filtering is added.

Unfiltered NIPA consumption performs fairly well. Using the "correct" unfilter parameter value of $\phi=.40$, the standard deviation of unfiltered NIPA consumption is very close to the value of true consumption, and the covariance is 0.24 in contrast to 0.09 for NIPA consumption. The GMM estimate of risk aversion is 22, which is still biased upwards, however, it 
Figure 1: Relative Risk Aversion Estimates in a Simulated Asset Pricing Economy

The figure shows the simulated distribution of GMM-based relative risk aversion estimates of true consumption, time aggregated and filtered NIPA consumption, and unfiltered NIPA consumption $(\phi=.40)$ in a consumption-based asset pricing economy with a true coefficient of relative risk aversion of 15 . See Table 1 for details.

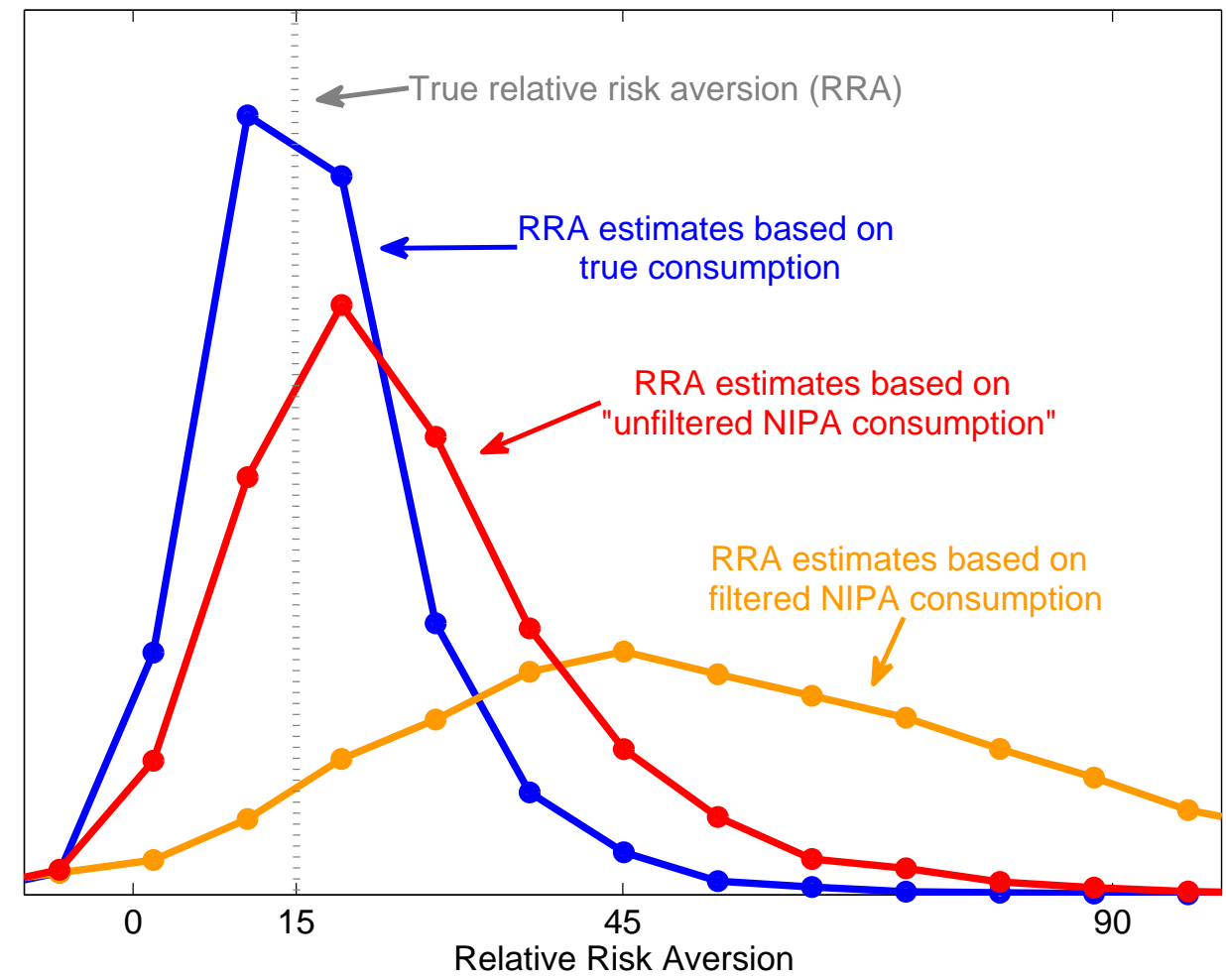

is now much closer to true risk aversion compared to estimates based on the original NIPA consumption measure. Figure 1 illustrates this point showing the simulated distribution of relative risk aversion estimates of true consumption, time aggregated and filtered NIPA consumption, and unfiltered NIPA consumption.

\section{Asset Pricing without Garbage}

Filtering can be harmful for consumption-based asset pricing, and may explain the relative success of alternative consumption measures. Thus, I calibrate the structural model of Section 2 to bring unfiltered NIPA consumption close to garbage. Afterwards, I will compare unfiltered NIPA consumption, garbage, P-J, and Q4Q4 in common asset pricing applications. 


\subsection{Comparison of Alternative Consumption Measures}

Panel A of Table 2 shows well-known statistics for NIPA annual real per capita consumption growth based on nondurables and services, as well as for nondurables and services separately. Details on data sources and construction is provided in Appendix B. Results are reported for the full sample period from 1927 to 2011 and the post-war sample from 1950 to 2011 . I treat garbage as observable consumption, which should not be subject to filtering or time aggregation. ${ }^{12}$ Data on garbage is only available for the post-war period, the period from 1960 to 2011. I use the empirical moments of garbage to calibrate unfiltered NIPA consumption using the parameter $\phi$ as in Equation (9).

\footnotetext{
${ }^{12}$ The assumption that garbage is not filtered is in line with the empirical properties of garbage and is based on the estimation methodology of garbage discussed in the internet appendix to Savov (2011). The assumption that garbage is not subject to time aggregation is more difficult to make. However, the empirical properties of garbage hardly point to a time aggregation effect (this observation is also mentioned in the internet appendix to Savov (2011)). Treating garbage as not time aggregated for the calibration of the unfilter rule is conservative in any case. Otherwise the true covariance of stock returns with consumption would be larger by a factor of two and the correlation by a factor of one and a half.
} 
Table 2: Empirical Properties of Alternative Consumption Measures

The table reports empirical moments of U.S. annual real per capita consumption growth measures. Nondurables and services are obtained from NIPA. Statistics on Garbage are are based on a slightly shorter sample period from 1960 to 2007 . Panel B and Panel C show three unfilter rules for the NIPA consumption measure. P-J is three-year NIPA consumption growth (Parker and Julliard (2005)). Q4Q4 is fourth-quarter to fourth-quarter NIPA consumption growth (Jagannathan and Wang (2007)). The third is the direct unfilter rule, as in Equation (9), using two different values for the unfilter parameter $\phi$. The lower value of $\phi$ is chosen to calibrate unfiltered NIPA consumption to match garbage in the post-war sample. The other value of $\phi$ serves as a sensitivity check.

Panel A NIPA Consumption and Garbage

\begin{tabular}{|c|c|c|c|c|c|c|c|}
\hline & \multirow{2}{*}{\multicolumn{3}{|c|}{$\begin{array}{c}\text { Full Sample }(1927-2011) \\
\text { NIPA Consumption }\end{array}$}} & \multicolumn{4}{|c|}{ Post-War Sample (1950 - 2011) } \\
\hline & & & & \multirow[b]{2}{*}{ Garbage } & \multicolumn{3}{|c|}{ NIPA Consumption } \\
\hline & $\begin{array}{l}\text { Nond. \& } \\
\text { Serv. }\end{array}$ & Nond. & Serv. & & $\begin{array}{l}\text { Nond. \& } \\
\text { Serv. }\end{array}$ & Nond. & Serv. \\
\hline Mean \% & 1.81 & 1.38 & 2.13 & 1.47 & 1.91 & 1.34 & 2.31 \\
\hline St. dev. \% & 2.22 & 2.65 & 2.15 & 2.88 & 1.30 & 1.55 & 1.34 \\
\hline Autocorr. & 0.39 & 0.27 & 0.52 & -0.14 & 0.43 & 0.25 & 0.54 \\
\hline Corr. $R_{M}^{e}$ & 0.12 & 0.17 & 0.08 & 0.58 & 0.01 & 0.09 & -0.01 \\
\hline Cov. $R_{M}^{e} \times 100$ & 0.06 & 0.10 & 0.03 & 0.27 & 0.00 & 0.03 & -0.00 \\
\hline
\end{tabular}

Panel B

Unfiltered NIPA Consumption: Nondurables \& Services

\begin{tabular}{lcccccccc}
\hline & \multicolumn{3}{c}{ Full Sample $(1927-2011)$} & & \multicolumn{3}{c}{ Post-War Sample $(1950-2011)$} \\
\cline { 2 - 4 } \cline { 6 - 8 } & P-J & $\phi=.53$ & $\phi=.40$ & & P-J & Q4-Q4 & $\phi=.53$ & $\phi=.40$ \\
\hline Mean $\%$ & 5.54 & 1.75 & 1.71 & & 5.75 & 1.91 & 1.92 & 1.93 \\
St. dev. $\%$ & 4.99 & 3.93 & 5.35 & & 3.07 & 1.48 & 2.22 & 3.00 \\
Autocorr. & 0.77 & -0.05 & -0.15 & & 0.80 & 0.31 & 0.01 & -0.09 \\
Corr. $R_{M}^{e}$ & 0.41 & 0.20 & 0.21 & & 0.18 & 0.34 & 0.17 & 0.21 \\
Cov. $R_{M}^{e} \times 100$ & 0.42 & 0.16 & 0.24 & & 0.10 & 0.09 & 0.07 & 0.11 \\
\hline
\end{tabular}

Panel C

Unfiltered NIPA Consumption: Nondurables excluding Services

\begin{tabular}{lcccccccc}
\hline & \multicolumn{3}{c}{ Full Sample $(1927-2011)$} & & \multicolumn{3}{c}{ Post-War Sample $(1950-2011)$} \\
\cline { 2 - 4 } \cline { 6 - 8 } & P-J & $\phi=.80$ & $\phi=.53$ & & P-J & Q4-Q4 & $\phi=.80$ & $\phi=.53$ \\
\hline Mean $\%$ & 4.20 & 1.36 & 1.32 & & 4.02 & 1.33 & 1.34 & 1.36 \\
St. dev. \% & 5.54 & 3.21 & 4.96 & & 3.13 & 1.95 & 1.88 & 2.90 \\
Autocorr. & 0.71 & 0.08 & -0.15 & & 0.74 & 0.12 & 0.09 & -0.13 \\
Corr. $R_{M}^{e}$ & 0.43 & 0.22 & 0.26 & & 0.23 & 0.41 & 0.15 & 0.23 \\
Cov. $R_{M}^{e} \times 100$ & 0.49 & 0.14 & 0.26 & & 0.13 & 0.14 & 0.05 & 0.12 \\
\hline
\end{tabular}

In Panel A, focusing on the post-war sample at the right hand side of the table, the standard deviation of reported NIPA nondurables and services is less than one-half the standard deviation of garbage, and the first-order autocorrelation is about 0.57 larger. The stock market covariance of the traditional NIPA measure is virtually zero, in contrast to 0.27 for 
garbage. These two findings combined can hardly be explained by time aggregation alone, but are reasonably in line with an additional effect of filtering, as documented in the simulation experiment of the previous section. There is also evidence of filtering when looking separately on NIPA nondurables and NIPA services. The standard deviation of NIPA services is lower than the standard deviation of NIPA nondurables, autocorrelation is larger, and the measured stock market covariance is smaller (even negative). The time aggregation bias should be the same for both time series. However, these differences are plausible if consumption data is filtered. If measurement error for NIPA services are larger than for NIPA nondurables, the parameter $\phi$ should be lower for NIPA services, implying a more aggressive filter. There is ample evidence in the official "NIPA handbook" that services are indeed more imprecisely measured (BEA (2009)).

Panel B compares several unfilter rules for NIPA nondurables and services, the most common consumption measure in asset pricing. Unfiltered NIPA consumption is able to match garbage quite closely with a calibrated value of $\phi=.40$. This corresponds to a pure filter $\nu$ of $1 / 2$, after accounting for time aggregation $(\phi=.80 \times \nu)$. The covariance of unfiltered NIPA nondurables and services is about 0.11 and larger than for the P-J measure and the Q4Q4 measure.

Wilcox (1992) concludes that "from the perspective of the measurement system, the usual two-part disaggregation (motivated from theory) into (i) durables and (ii) nondurables plus services does not make much sense". Wilcox suggests to distinguish between nondurables and services in empirical work. Similarly, Savov (2011) suspects that particularly the way in which services are measured and estimated is rather harmful for the NIPA measure and may (partly) explain differences to garbage. For this reason, I also consider NIPA nondurables excluding services in Panel C. ${ }^{13}$ In comparison to Panel B, I find that standard deviations increase, autocorrelations decrease, and most importantly, correlations and covariances to the stock market further increase for all measures. ${ }^{14}$ The direct unfilter method is able to match the properties of garbage closely for a more moderate unfilter parameter $\phi$ of only .53

\footnotetext{
${ }^{13}$ Hall (1988), among others, tests nondurables excluding services as well.

${ }^{14}$ Interestingly, the qualitative improvements are once again in line with the Monte Carlo experiment. As an example, when filtering is likely to be lower, as in Panel C, the improvement to the covariance of the Q4Q4 measure is large relatively to the P-J measure.
} 
(corresponding to $\nu=2 / 3$, as in the simulation). Again, a higher value of $\phi$ is in line with less measurement error in NIPA nondurables than in NIPA services. Time series plots of the alternative consumption measures are provided in Figure 2.

In summary, I find that time aggregation does not suffice to explain the empirical properties of NIPA consumption as well as alternative measures such as P-J and Q4Q4. Although the filter proposed in this paper is a clear simplification of reality, it is sufficient to match important aspects of the data surprisingly well and brings the properties of unfiltered NIPA consumption close to garbage.

\subsection{Equity Premium}

Model. I test the Euler equation implied by the consumption-based asset pricing model (Lucas (1978), Breeden (1979)) as stated in Equation (10). I follow Savov (2011), among others, and fix $\beta=.95$ to focus on relative risk aversion. It is well known that estimates of the relative risk aversion obtained from this Euler equation are typically too high from a theoretical perspective (Hansen and Singleton (1982), Mehra and Prescott (1985)). The risk-free rate puzzle, termed by Weil (1989), is related to the equity premium puzzle. High coefficients of relative risk aversion imply a high desire for consumption smoothing, resulting in implausibly large real risk-free interest rates. A log approximation of Equation (10) yields for the risk-free rate (e.g., Campbell, Lo, and MacKinlay (1997)):

$$
r_{f}=-\log (\beta)+\gamma E\left[\log \left(C_{t+1} / C_{t}\right)\right]-\frac{1}{2} \gamma^{2} \operatorname{Var}\left[\log \left(C_{t+1} / C_{t}\right)\right]
$$

Following Savov (2011) when testing Equation (10), I also report this implied risk-free rate. Furthermore, the empirically observed risk-free rate can be directly included as a test asset in addition to Equation (10):

$$
E\left[\beta\left(\frac{C_{t+1}}{C_{t}}\right)^{-\gamma} R_{f, t+1}-1\right]=0,
$$

where the estimation procedure is forced to match the equity premium jointly with the empirical risk-free rate. Estimation is carried out by Generalized Method of Moments (GMM) 
Figure 2: NIPA Consumption Measures

The figure shows annual real per capita NIPA consumption growth from 1927 to 2011. The upper figure shows NIPA nondurables and services, and the lower figure shows NIPA nondurables excluding services. The consumption measures are NIPA consumption without unfaltering, unfiltered NIPA consumption, threeyear NIPA consumption (P-J) as in Parker and Julliard (2005), and fourth-quarter to fourth-quarter NIPA consumption (Q4Q4) as in Jagannathan and Wang (2007).
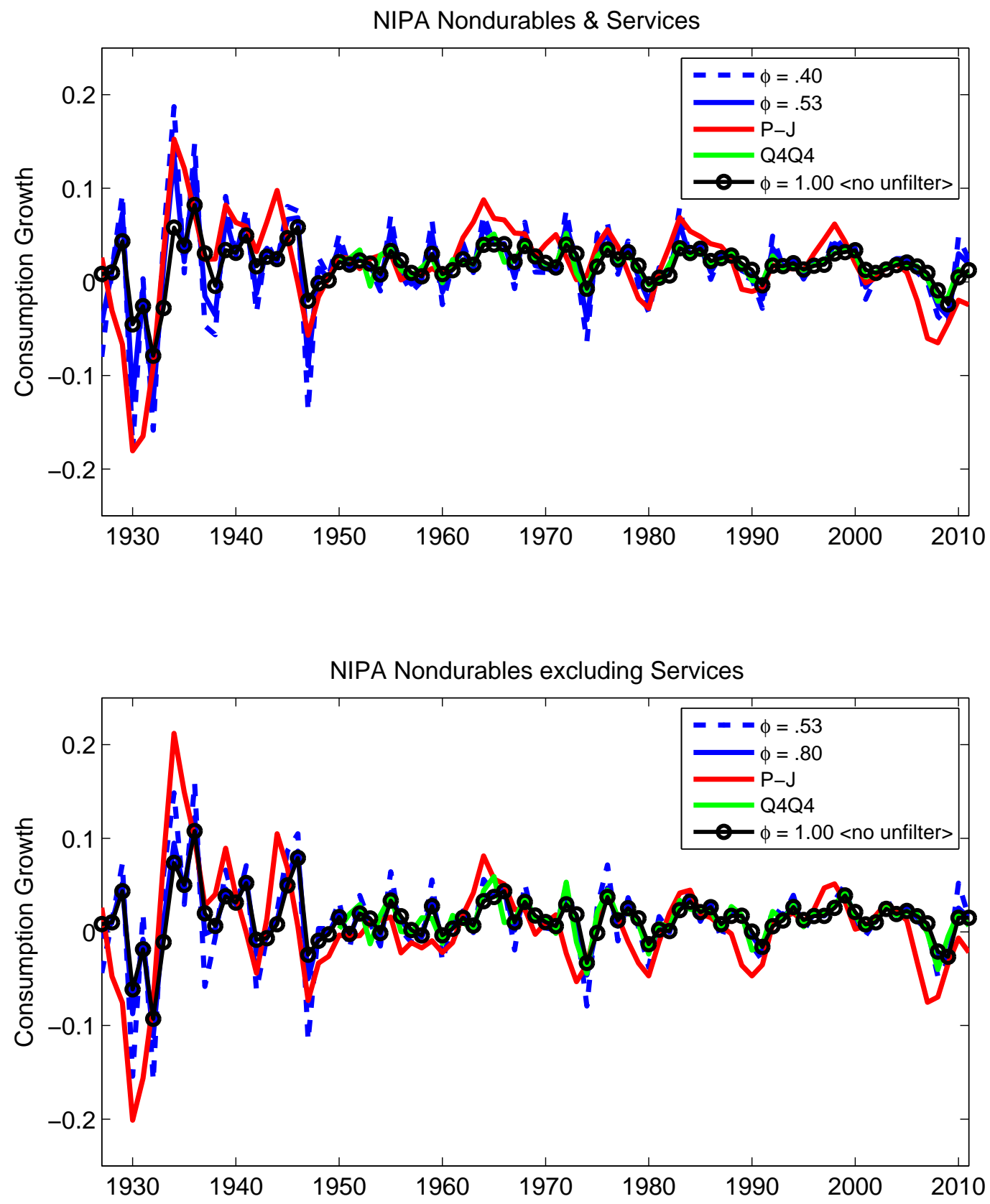
with Newey and West (1987) standard errors (three lags, and removed moment means). I report the mean absolute error (MAE) of the moment condition(s), to check if the Euler equation errors are economically large (Lettau and Ludvigson (2009)), and the p-value to the J-test of overidentified restrictions.

Results: NIPA Nondurables and Services. Table 3 provides GMM estimates for the coefficient of relative risk aversion for unfiltered NIPA nondurables and services. The table is split into a full sample period from 1927 to 2011 and a shorter post-war sample period from 1950 to 2011. Garbage and the Q4Q4 measure are only available in the post-war sample. As shown in the previous section, the calibrated unfilter parameter which brings NIPA nondurables and services close to garbage is equal to $\phi=.40(\nu=1 / 2)$. I also report results for a larger parameter, $\phi=.53(\nu=2 / 3)$, to provide some comparative analysis on the effect of the unfilter parameter. Finally, the table also provides results for the traditional NIPA consumption measure $(\phi=1)$.

In Panel A, the equity premium is the only test asset. In the full sample, the traditional NIPA consumption measure requires a coefficient of relative risk aversion of 34, with an implied risk-free rate of $38 \%$. In contrast, unfiltered NIPA consumption $(\phi=.40)$ requires a low estimate of 12 with an implied risk-free rate of only $5 \%$. The ultimate consumption risk measure proposed by Parker and Julliard (2005) produces a relatively low coefficient of relative risk aversion of 9 , but goes hand in hand with a large risk-free rate of $45 \%$.

Related research (e.g. Campbell (2003), Engsted and Møller (2011)) has shown that excluding the turbulent periods in the first half of the 20th century substantially increases the equity premium (and risk-free rate) puzzle. In line with the literature, as shown in Table 3, the traditional NIPA consumption measure requires a relative risk aversion of 59 with a risk-free rate of $89 \%$ in the post-war period and still produces a MAE of $3.2 \%$. In contrast, garbage as an alternative consumption measure matches the equity premium with a relative risk aversion of only 15 and an implied risk-free rate of 18\%. The P-J and Q4Q4 measures perform better than traditional NIPA consumption, but still substantially worse than garbage. The table shows that both measures have difficulties particularly with matching the risk-free rate. I find that unfiltered NIPA consumption is closer to garbage. When setting the parameter $\phi$ to 


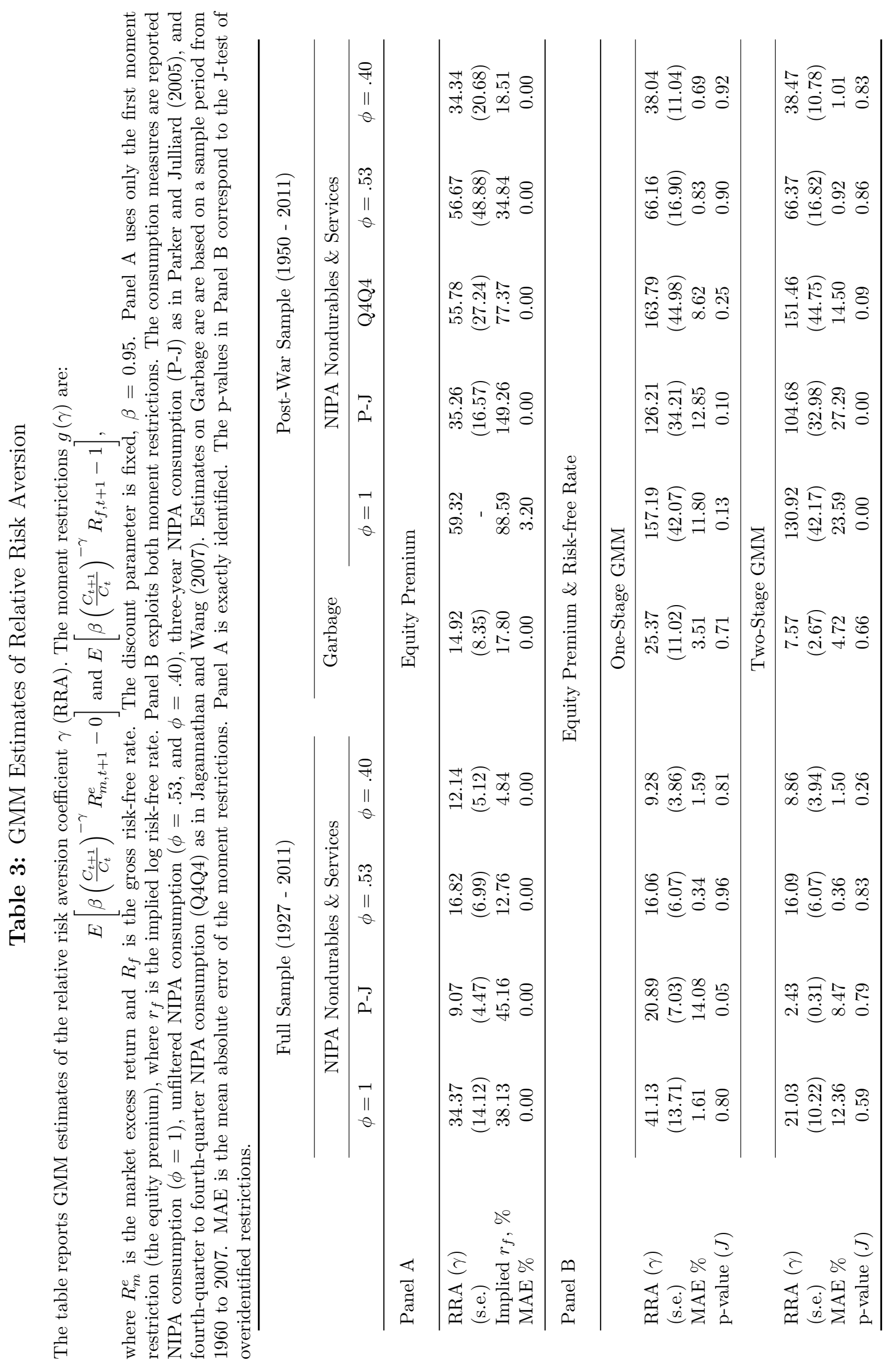


.40 , the coefficient of relative risk aversion in the post-war sample is 34 , which is within one standard error to 15. Similarly, the implied risk-free rate of unfiltered NIPA consumption is $19 \%$, close to garbage as well $(18 \%)$. In the post-war period, the estimated coefficients of relative risk aversion for unfiltered NIPA consumption and garbage are still high but much smaller than for the other NIPA-based consumption measures.

Panel B forces GMM to fit both, the equity premium and the empirical risk-free rate at the same time. The traditional NIPA consumption measure, the P-J measure, and the Q4Q4 measure fail to fit both moment conditions even with a large relative risk aversion, as indicated by a large MAE. In contrast, unfiltered NIPA consumption performs considerably better. Relative risk aversion coefficients are lower, and the MAE of the moment conditions is relatively small. In particular, results for the full sample show that unfiltered NIPA consumption requires a relative risk aversion as small as 9 . In the post-war sample, relative risk aversion is higher, around 38, which is nevertheless four times lower than for traditional NIPA consumption, and thus again much closer to garbage.

Results: NIPA Nondurables Excluding Services. Given the measurement methodology of consumption, Wilcox (1992) argues that the services component in NIPA consumption could be harmful for empirical applications. To quantify the impact of services, Table 4 provides results for alternative consumption measures based on NIPA nondurables excluding services. Less measurement error also means less filtering, and thus, allows a larger value for the unfilter parameter. As shown in the previous section, the calibrated unfilter parameter which brings NIPA nondurables excluding services close to garbage is $\phi=.53(\nu=2 / 3)$. For comparison, the table also provides results for $\phi=.80(\nu=1)$.

Overall, I find that excluding services significantly improves the results of all NIPA-based alternative consumption measures, particularly in the post-war sample (1950 - 2011). For example, the Q4Q4 measure results in a coefficient of relative risk aversion of only 30, in contrast to 56 when services are included (Panel A). However, the P-J as well as the Q4Q4 measures both still experience problems fitting the risk-free rate. In contrast, using a modest parameter $\phi=.53$, unfiltered NIPA nondurables require a coefficient of relative risk aversion of only 26 with an implied risk-free rate of $12 \%$, which is indistinguishable from garbage. In 


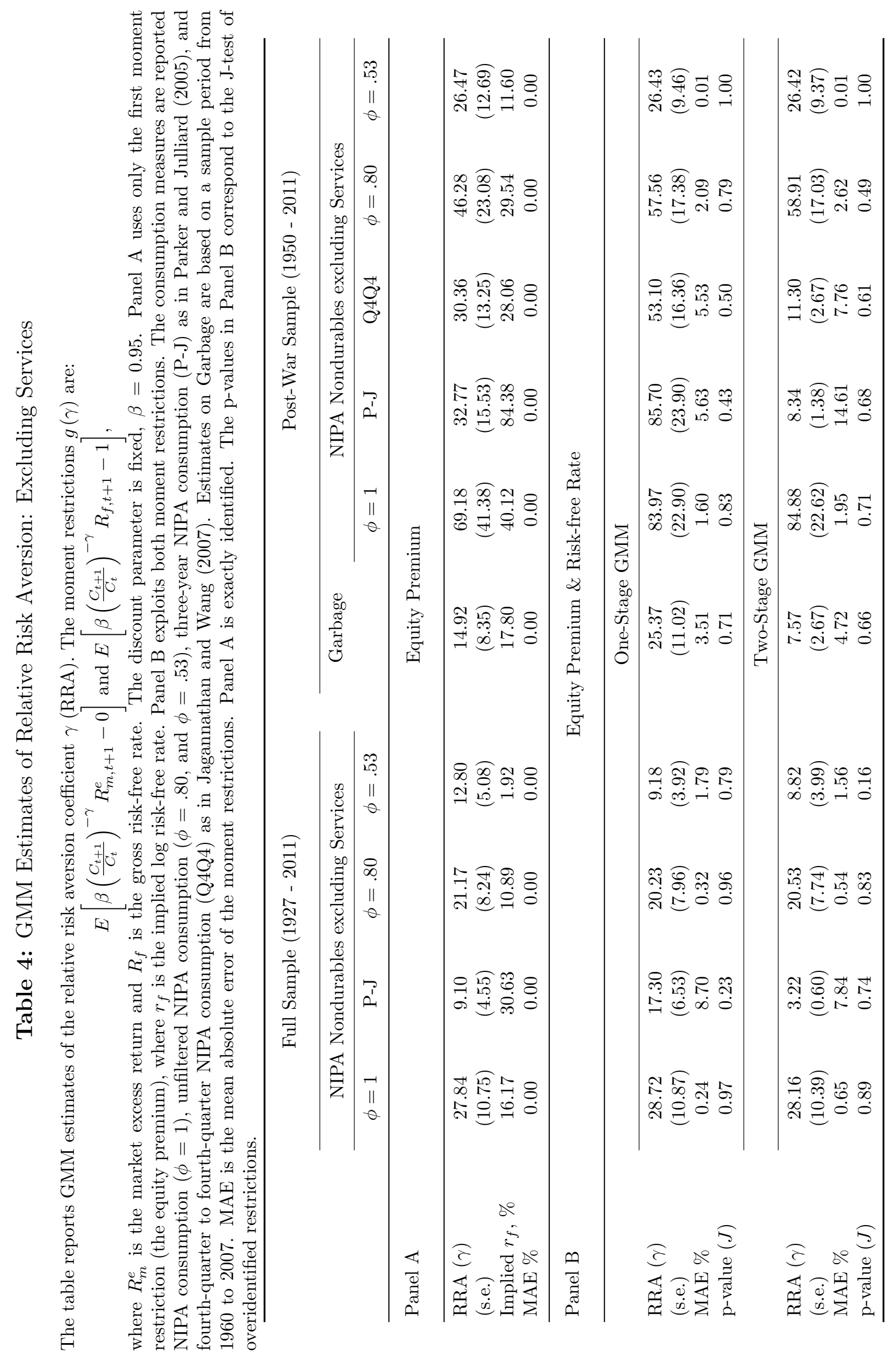


the long sample (1927 - 1951), I find a coefficient of relative risk aversion of 13 for unfiltered NIPA consumption, with an implied (real) risk-free rate of $2 \%$.

To summarize, I find that after accounting for filtering, it is possible to replicate the results of garbage relying only on NIPA consumption. For the longer sample starting in 1927, I find an even lower coefficient of relative risk aversion between 9 and 13 with a low implied risk-free rate between $2 \%$ and $5 \%$ which is close to theoretically plausible values.

\subsection{Cross-Section of Stock Returns}

Model. A linearized version of the consumption-based asset pricing model implies the following (cross-sectional) beta representation (Breeden, Gibbons, and Litzenberger (1989)):

$$
E\left[R_{i, t+1}^{e}\right]=\lambda_{0}+\lambda \beta_{i}
$$

where $E\left[R_{i, t+1}^{e}\right]$ is the expected excess return of asset $i$, and $\lambda_{0}$ is a common pricing error which should be zero by theory. The 25 Fama-French portfolios sorted by size and book-tomarket, available on the web site of Kenneth R. French, are used as test assets. The two-stage cross-sectional regression method of Fama and MacBeth (1973) can be used to estimate the specification in Equation (13). In a first step, consumption growth betas are estimated using a time-series OLS regression for each asset $i$. In a second step, a cross-sectional OLS regression on the first step betas is used to estimate the risk factor price $\lambda$.

The cross-sectional OLS estimates do not account for the fact that the betas themselves are estimated, nor do they account for heteroskedasticity and autocorrelation. Shanken (1992) provides adjustments for the standard errors with respect to the errors in variables problem. Cochrane (2005) shows how to use the GMM procedure to account for both issues. For GMM-based inference, I apply the parametric VARHAC method described by den Haan and Levin (2000). Burnside (2011) argues that if some factors are persistent, as is particularly the case for the P-J measure, the GMM-VARHAC should be preferred to the Newey-West approach to calculate standard errors. ${ }^{15}$ The weighting matrix is set up such that the point

\footnotetext{
${ }^{15}$ To implement the GMM-VARHAC, I apply the VARHAC matlab code with the same settings as Burnside (2011) available to the online appendix of Burnside's paper on http://www.aeaweb.org.
} 
estimates of the GMM procedures are identical to the traditional Fama-MacBeth regressions (details are provided in Cochrane (2005), and Burnside (2011)).

I report the cross-sectional $R^{2}$, the mean absolute error (MAE), and a $\chi^{2}$-test on the 25 pricing errors of the model (Cochrane (2005, p.234)) as measures of model fit.

Results: NIPA Nondurables and Services. Table 5 shows the cross-sectional regression results for NIPA nondurables and services using the full sample (1927 - 2011) and the shorter post-war sample $(1950$ - 2011). The discussion focuses on the post-war sample. Simple NIPA consumption $(\phi=1)$ as a risk factor results in a large and significant constant (9.5\%), and a low cross-sectional fit $\left(R^{2}=0.28\right)$. Garbage has difficulties in pricing the 25 FamaFrench portfolios, and shows no advantage compared to NIPA consumption when a constant is included to the model. The P-J and Q4Q4 measures perform better. The constants $\left(\lambda_{0}\right)$ are insignificant based on GMM-VARHAC t-statistics, close to zero for the Q4Q4 measure, and risk factors $(\lambda)$ are significant for the alternative NIPA-based consumption measures. For both, the one-factor consumption model explains more than one-half of the cross-sectional variation of average returns.

The new consumption measure, unfiltered NIPA consumption, performs similarly to P-J and Q4Q4. Using the calibrated unfilter parameter $\phi=.40$, the constant is not significant and the risk factor is significantly priced in the cross-section of stock returns with a slope coefficient of $4.3 \%$. The $R^{2}$ is about 0.59 , which is as large as for the P-J and Q4Q4 measures. The mean absolute error of unfiltered NIPA consumption is $1.4 \%$, close to P-J $(1.2 \%)$ and Q4Q4 (1.3\%). However, based on GMM inference, all models are rejected by the $\chi^{2}$ test on the 25 pricing errors at the $5 \%$ level. At the bottom of the table, the cross-sectional regressions are repeated with the restriction of a zero constant. I find that in the post-war sample, consumption is only significantly (5\% level) priced when using the Q4Q4 measure, and, in contrast to when a constant is included, for the garbage measure. In the longer sample period, the estimated risk premium is significant for all considered consumption measures with the exception of traditional NIPA consumption $(\phi=1)$. 


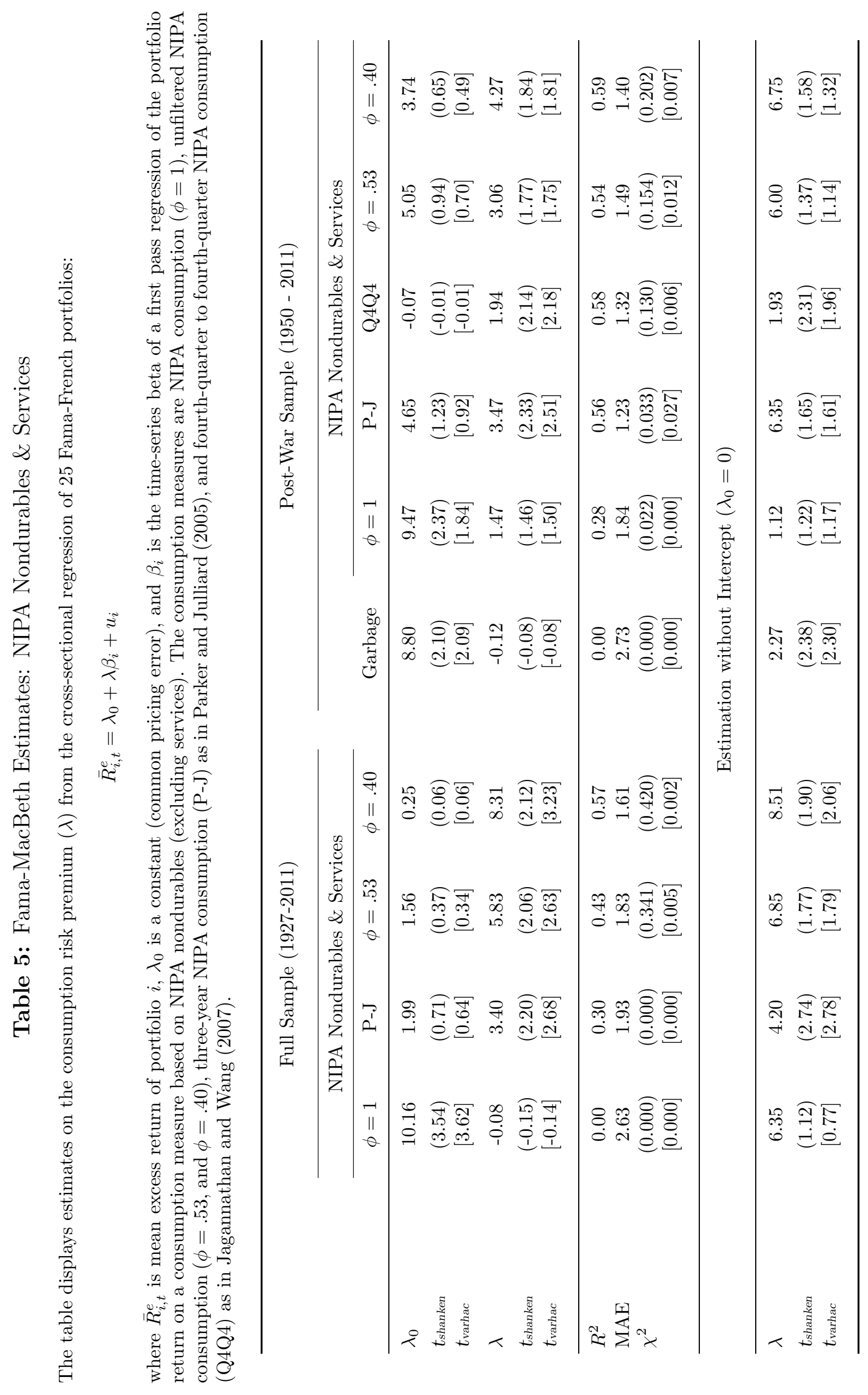


Results: NIPA Nondurables Excluding Services. Table 6 provides the cross-sectional regression results for NIPA nondurables excluding services. I find that excluding services improves some aspects of the cross-sectional model, particularly in the post-war sample from 1950 to 2011. Common pricing errors and MAEs are lower and the cross-sectional $R^{2}$ is larger for almost all NIPA-based consumption measures. For unfiltered NIPA consumption $(\phi=.53)$, the constant is only $0.9 \%$ and the $R^{2}$ is 0.62 . However, based on GMM inference and when estimation is without an intercept and the sample period is restricted to 1950-2011, the risk factor premium is not significant ( $5 \%$ level) for unfiltered NIPA nondurables. Again, taking the full sample period from 1927 to 2011 leads to t-statistics well above two and points to significance.

Consumption Betas. It is useful to verify the cross-sectional regression results on the consumption risk premium with a look at the first-step consumption betas, or risk exposures, of the individual test assets. Small stocks have larger average returns than big stocks. High book-to-market stocks (value stocks) have larger average returns than low book-to-market stocks (growth stocks). Accordingly, the first step consumption betas should have respective spreads to provide a reasonable explanation for differences in average returns.

Figure 3 provides the underlying consumption betas of Table 5 and Table 6 , for reported NIPA consumption $(\phi=1)$ and unfiltered NIPA consumption $(\phi=\{.53, .40\}$ for NIPA nondurables and services and $\phi=\{.80, .53\}$ for NIPA nondurables excluding services). Overall, the consumption betas for reported NIPA consumption hardly show any systematic size or value exposure. However, the unfiltered NIPA consumption measures show a smooth ramp up from big to small stocks and from growth to value stocks. Filtering and time aggregation in consumption data seem to hide the consumption risk exposure of the Fama-French portfolio returns. The simple unfilter formula of Equation (9) goes a long way in recovering betas which are in line with theory. 


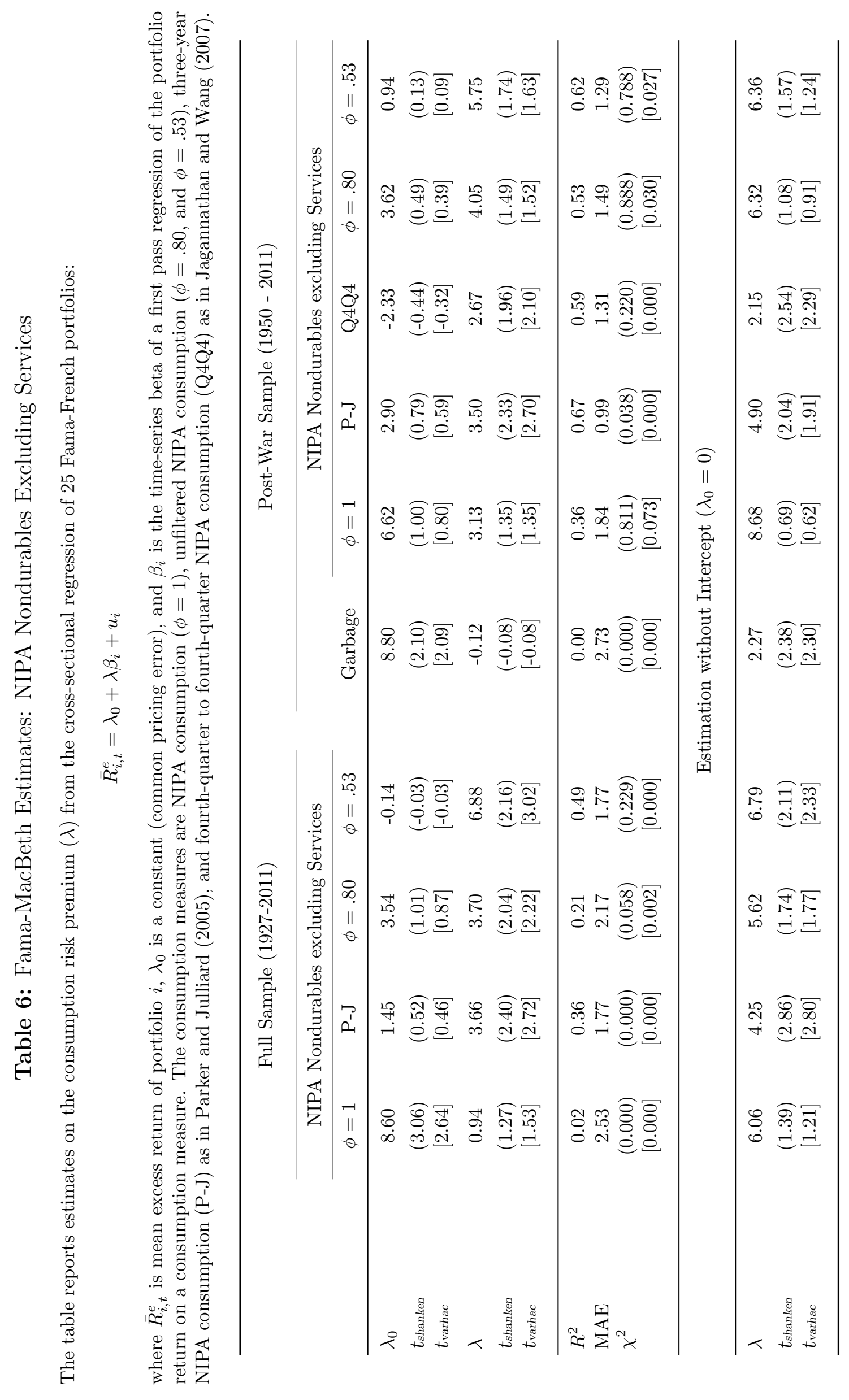


Figure 3: Consumption Betas

The figure shows time-series betas of a first pass regression of 25 Fama-French size and book-to-market portfolio returns on a consumption measure based on NIPA nondurables and services and NIPA nondurables (excluding services). The consumption measures are reported NIPA consumption $(\phi=1.0)$ and unfiltered NIPA consumption; with $\phi=.53, \phi=.40$ for NIPA nondurables and services, and $\phi=.80, \phi=.53$ for NIPA nondurables (excluding services). The estimation period is from 1927 to 2010.

Nond. \& Serv. $(\phi=1.0<$ no unfilter $>) \quad$ Nond. \& Serv. $(\phi=.53)$

Nond. \& Serv. $(\phi=.40)$
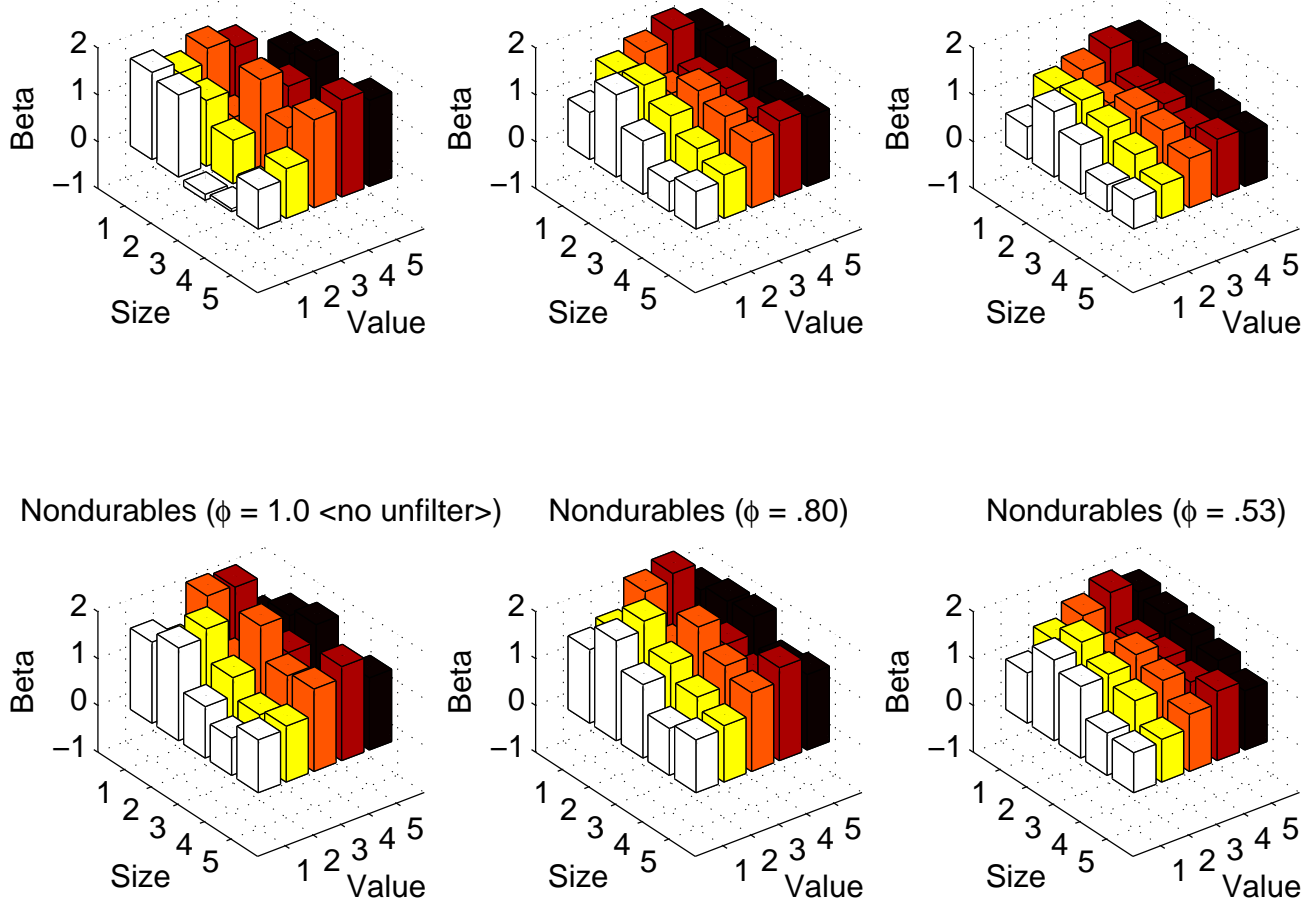


\subsection{Unfiltered Fourth Quarter Consumption}

It is probably possible to further improve the simple unfilter approach proposed in this paper. As a final remark, I consider a straightforward modification in this section. The simulation experiment provides evidence that using fourth-quarter to fourth-quarter consumption is effective in dissolving effects of time aggregation. In contrast, the unfilter method is more effective in dissolving the effects of filtering. Thus, a combination of both "unfilter rules" is promising.

I unfilter fourth-quarter NIPA consumption using Equation (9). Since the use of fourthquarter to fourth-quarter NIPA consumption already accounts for time aggregation, I only need to account for filtering. For this purpose, I use $\nu$ as implied by the calibration of Table 2 but set $a=1$, which gives $\phi=1 \times 1 / 2$ for NIPA nondurables and services and $\phi=1 \times 2 / 3$ for NIPA nondurables excluding services. The resulting standard deviation of unfiltered fourthquarter NIPA nondurables and services (and NIPA nondurables excluding services) is 2.9\% $(3.0 \%)$, with an autocorrelation of $-0.07(-0.10)$, and a stock market covariance of $0.27(0.27)$. These stochastic properties are very close to garbage (see Table 2).

Table 7 shows that it is possible to closely replicate the coefficient of relative risk aversion of garbage (about 15) using only NIPA consumption (as low as 19). Furthermore, the crosssectional slope coefficient on 25 Fama-French portfolios is closely replicated using unfiltered NIPA consumption as well (garbage: $2.7 \%$, without constant; $2.4 \%$ for unfiltered NIPA nondurables \& services and $2.6 \%$ for unfiltered NIPA nondurables excluding services, without constant), as shown in Table 8. Of course, this modification comes at the cost that I cannot include consumption data for the pre-war period. However, this result shows that, after accounting for filtering, garbage and NIPA consumption behave surprisingly similar. 
Table 7: Unfiltered Fourth Quarter Consumption: GMM Estimates of Relative Risk Aversion

The table reports GMM estimates of the relative risk aversion coefficient $\gamma(\mathrm{RRA})$. The moment restrictions $g(\gamma)$ are:

$$
E\left[\beta\left(\frac{C_{t+1}}{C_{t}}\right)^{-\gamma} R_{m, t+1}^{e}-0\right] \text { and } E\left[\beta\left(\frac{C_{t+1}}{C_{t}}\right)^{-\gamma} R_{f, t+1}-1\right] \text {, }
$$

where $R_{m}^{e}$ is the market excess return and $R_{f}$ is the gross risk-free rate. The discount parameter is fixed, $\beta=0.95$. Panel A uses only the first moment restriction (the equity premium), where $r_{f}$ is the implied log risk-free rate. Panel A uses only the first moment restriction (the equity premium), where $r_{f}$ is the implied $\log$ risk-free rate. Panel B exploits both moment restrictions. The consumption measures are unfiltered fourth-quarter NIPA nondurables \& services $(\phi=0.50)$, and fourth-quarter NIPA nondurables excluding services $(\phi=0.66)$.

Post-War Sample (1950 - 2011)

\begin{tabular}{|c|c|c|}
\hline & \multicolumn{2}{|c|}{ Unfiltered Fourth Quarter NIPA Consumption } \\
\hline & $\begin{array}{c}\text { Nondurables \& Serv. } \\
\qquad \phi=.50\end{array}$ & $\begin{array}{c}\text { Nondurables excl. Serv. } \\
\qquad \phi=.66\end{array}$ \\
\hline Panel A & \multicolumn{2}{|c|}{ Equity Premium } \\
\hline $\operatorname{RRA}(\gamma)$ & 22.52 & 18.98 \\
\hline (s.e.) & $(9.76)$ & $(8.51)$ \\
\hline Implied $r_{f}, \%$ & 27.38 & 14.40 \\
\hline MAE $(g), \%$ & 0.00 & 0.00 \\
\hline \multirow[t]{2}{*}{ Panel A } & \multicolumn{2}{|c|}{ Equity Premium \& $R_{f}$} \\
\hline & \multicolumn{2}{|c|}{ One-Stage GMM } \\
\hline $\operatorname{RRA}(\gamma)$ & 45.91 & 25.45 \\
\hline (s.e.) & $(11.79)$ & $(9.23)$ \\
\hline MAE $(g), \%$ & 4.31 & 1.96 \\
\hline \multirow[t]{2}{*}{ p-value $(J)$} & 0.57 & 0.81 \\
\hline & \multicolumn{2}{|c|}{ Two-Stage GMM } \\
\hline $\operatorname{RRA}(\gamma)$ & 8.73 & 11.13 \\
\hline (s.e.) & $(1.78)$ & $(4.42)$ \\
\hline MAE $(g), \%$ & 7.94 & 5.46 \\
\hline p-value $(J)$ & 0.49 & 0.49 \\
\hline
\end{tabular}


Table 8: Unfiltered Q4 Consumption: Fama MacBeth Regressions

The table reports estimates on the consumption risk premium $(\lambda)$ from the cross-sectional regression of 25 Fama-French portfolios:

$$
\bar{R}_{i, t}^{e}=\lambda_{0}+\lambda \beta_{i}+u_{i}
$$

where $\bar{R}_{i, t}^{e}$ is mean excess return of portfolio $i, \lambda_{0}$ is a constant (common pricing error), and $\beta_{i}$ is the timeseries beta of a first pass regression of the portfolio return on a consumption measure. The consumption measures are unfiltered fourth-quarter NIPA nondurables \& services $(\phi=0.50)$, and fourth-quarter NIPA nondurables excluding services $(\phi=0.66)$.

\begin{tabular}{lcc}
\hline & \multicolumn{2}{c}{ Post-War Sample (1950 - 2011) } \\
\cline { 2 - 3 } & Unfiltered Fourth Quarter NIPA Consumption \\
\cline { 2 - 3 } & Nondurables \& Serv. & Nondurables excl. Serv. \\
& $\phi=.50$ & $\phi=.66$ \\
\hline$\lambda_{0}$ & -1.93 & -1.33 \\
$t_{\text {shanken }}$ & $(-0.44)$ & $(-0.31)$ \\
$t_{\text {varhac }}$ & {$[-0.35]$} & {$[-0.25]$} \\
$\lambda$ & 2.91 & 2.99 \\
$t_{\text {shanken }}$ & $(2.32)$ & $(2.06)$ \\
$t_{\text {varhac }}$ & {$[2.44]$} & {$[2.31]$} \\
\hline$R^{2}$ & 0.59 & 0.51 \\
MAE & 1.30 & 1.39 \\
$\chi^{2}$ & $(0.018)$ & $(0.019)$ \\
& {$[0.000]$} & {$[0.000]$} \\
\hline & & \\
& Estimation without intercept \\
\hline$\lambda$ & & 2.63 \\
$t_{\text {shanken }}$ & 2.43 & $(2.86)$ \\
$t_{\text {varhac }}$ & $(2.95)$ & {$[2.71]$} \\
\hline & {$[2.74]$} & \\
\hline
\end{tabular}




\section{Conclusion}

This paper provides an explanation of why garbage-based asset pricing works better than NIPA consumption-based asset pricing. NIPA statisticians filter observable consumption to mitigate measurement error and to receive "optimal" estimates of the level of consumption. Garbage is not subject to such filtering and shares the properties of observable consumption. From an asset pricing perspective, observable consumption is eligible for calculating consumption covariances and there is no rationale to apply a filter on it. On the contrary, I show that filtering in combination with time aggregation is disastrous for gauging consumption risk of stock returns. I apply a structural model to the NIPA consumption measurement procedure and can reconcile three successful alternative consumption measures: garbage (Savov (2011)), fourth-quarter to fourth-quarter NIPA consumption (Jagannathan and Wang (2007)), and three-year NIPA consumption (Parker and Julliard (2005)).

First, the model explains the relative success of garbage over reported NIPA consumption. This is important, since in the light of the evidence provided it seems unlikely that the success of garbage in measuring consumption is just a coincidence. Furthermore, unfiltered NIPA consumption allows the use of very long time series, a substantial limitation of other alternative consumption measures. Second, the paper is able to provide a unifying explanation of further alternative NIPA-based consumption measures proposed in recent literature, specifically three-year and fourth-quarter to fourth-quarter consumption growth. I find that these two measures can be interpreted as ad hoc unfilter rules, where the former is effective in reducing filtering and the latter is effective in reducing time aggregation. Finally, in the big picture, the paper provides evidence that there is valuable information in macroeconomic data for the purpose of asset pricing which, however, is burrowed due to the "appraisal" process. Future research could evaluate how to modify these processes such that macroeconomic data optimized for the specific needs of financial research can be made available and, thus, making asset pricing without garbage ultimately true. 


\section{Appendix}

\section{A Simulation Details}

Model. This section provides details on how I generate the data of the model economy in which asset pricing does work. The Euler equation satisfies the pricing restriction:

$$
E_{t}\left[\exp \left(\ln (\beta)-\gamma \triangle c_{t+1}+r_{m, t+1}\right)\right]=1,
$$

where $r_{m, t+1}=\ln \left(R_{M, t+1}\right)$ is the log stock market return and $\triangle c_{t+1}=\ln \left(C_{t+1} / C_{t}\right)$ is $\log$ consumption growth. Both are driven by the following dynamics:

$$
\begin{gathered}
\triangle c_{t+1}=\mu+\sigma \eta_{t+1}, \\
\triangle d_{t+1}=\mu_{d}+\varphi_{d} \sigma u_{t+1}+\pi_{d} \sigma \eta_{t+1}, \\
u_{t+1}, \eta_{t+1} \sim N(0,1),
\end{gathered}
$$

where $\triangle d_{t+1}$ is log dividend growth. This model is the canonical CCAPM case of Bansal and Yaron (2004), and can be solved for the process of the stock market return and the risk-free rate as described in their paper. In the particular, the log stock market return at time $t+1$ is given by:

$$
r_{m, t+1}=-\ln (\beta)+\gamma \mu-\frac{1}{2}\left[\left(\pi_{d}-\gamma\right)^{2} \sigma^{2}+\varphi_{d} \sigma^{2}\right]+\varphi_{d} \sigma u_{t+1}+\pi_{d} \sigma \eta_{t+1},
$$

and the implied log risk-free interest rate is:

$$
r_{f}=-\ln (\beta)+\gamma \mu-\frac{1}{2} \gamma^{2} \sigma^{2} .
$$

For a given set of parameter values $\left(\beta, \gamma, \mu, \sigma, \mu_{d}, \varphi_{d}, \pi_{d}\right)$, I can simulate consumption growth and the model implied equity premium, $r_{m, t+1}-r_{f}$.

Parameters. Table A.1 reports the parameter values which I use to simulate monthly data. These parameters are calibrated such that simulated "true" consumption growth has similar characteristics as garbage. Benchmarking to garbage is useful, since we know from Savov (2011) that the stochastic properties of garbage can match the equity premium in the data quite well.

The empirical correlation between the stock market and garbage is about 0.60 and the annual standard deviation of garbage is 3\%. I set the dividend consumption exposure parameter to 3.8 and consumption volatility to the according annual value of $3 \%$ to generate similar properties for true consumption growth in the model economy. The coefficient of relative risk aversion of 15 together with the other parameters implies an annual expected equity premium of $5.1 \% .{ }^{16}$ Finally, I set the dividend leverage parameter to 5.5 to generate annual stock market volatility of $20 \%$. The time discount factor, the mean of consumption growth, and the mean of dividend growth do not effect the equity premium and are set to common values in the related literature.

\footnotetext{
${ }^{16}$ The expected equity risk premium in this model economy is $E\left(r_{m, t+1}-r_{f}\right)+\frac{1}{2} \operatorname{Var}\left(r_{m, t+1}\right)=\gamma \pi_{d} \sigma^{2}$.
} 
Table A.1: Parameter Values for the Simulated Asset Pricing Economy

\begin{tabular}{lcc}
\hline & Variable & Value \\
\hline Risk Aversion & $\gamma$ & 15 \\
Time Discount Factor & $\beta$ & $0.988^{1 / 12}$ \\
Mean Consumption Growth & $\mu$ & $0.01 / 12$ \\
Consumption Volatility & $\sigma$ & $0.03 /\left(12^{1 / 2}\right)$ \\
Mean Dividend Growth & & $0.01 / 12$ \\
Dividend Consumption Exposure & $\mu_{d}$ & 3.8 \\
Dividend Leverage & $\pi_{d}$ & 5.5 \\
\hline
\end{tabular}

Adding Time Aggregation and Filtering. I convert simulated monthly log consumption growth rates and log returns into simple growth rates and simple returns, and also produce a series of monthly consumption levels. The table in the main paper display statistics for the annual simple growth rates of consumption, to be comparable to the empirical part of the paper. Time aggregation and filtering are then added to the data as follows: The subscript consists of a month index $m$ running from one to twelve and a year index $t$ running from zero to $T$. The year $t+1$ consumption growth rate is based on "December" levels:

$$
\triangle C_{t+1}=C_{12 ; t+1} / C_{12 ; t}-1 .
$$

The year $t+1$ consumption growth rate with time aggregation ("TA") is calculated as:

$$
\triangle c_{t+1}^{T A}=\log \left(\sum_{m=1}^{12} C_{m ; t+1} / \sum_{m=1}^{12} C_{m ; t}\right) \quad \triangle C_{t+1}^{T A}=\exp \left(1+\triangle c_{t+1}^{T A}\right)-1 .
$$

To simulate a filter, I assume that the variance of (individual consumption component) measurement error is as large as the variance of true consumption growth, which gives $\nu=$ $1 / 2$. For aggregate consumption, measurement error diversifies and is infinitesimal small and only the filter carries over. Thus I directly apply the simulated filter on aggregate log consumption:

$$
\begin{gathered}
c_{t+1}^{T A F}=1 / 2 \times c_{t+1}^{T A}+(1-1 / 2) \times c_{t}^{T A F} \\
\triangle c_{t+1}^{T A F}=c_{t+1}^{T A F}-c_{t}^{T A F} \quad \triangle C_{t+1}^{T A F}=\exp \left(1+\triangle c_{t+1}^{T A F}\right)-1 .
\end{gathered}
$$

The resulting year $t+1$ consumption is subject to time aggregation and filtering ("TAF") and corresponds to consumption as reported in NIPA. The equity premium is based on "December" levels, and is used to calculate the correlations and covariances of all investigated consumption measures.

Unfiltering. I compare three different "unfilter" rules for "time aggregated" and "time aggregated and filtered" consumption. First, I apply the new method to the simulated data:

$$
\triangle c_{t+1}^{\phi}=\left[\triangle c_{t+1}^{n}-(1-\phi) \triangle c_{t}^{n}\right] / \phi, \quad n=T A, T A F,
$$




$$
\triangle C_{t+1}^{\phi}=\exp \left(1+\triangle c_{t+1}^{\phi}\right)-1
$$

Since the data-generating process and the used filter are known within the simulation experiment, it is possible to anticipate an unfilter parameter which yields a good result in matching "true" consumption growth. Using the approximation $\phi=.80 \times \nu$ gives a parameter of $\phi=.80$ if the data is not filtered $(\nu=1)$, and of $\phi=.40$ if the data is filtered $(\nu=1 / 2)$. As a sensitivity check, results are presented for $\phi$ equal to $.80, .53$, and .40 , for both, "time aggregated" and "time aggregated and filtered" consumption.

Second, I consider three-year consumption (P-J) following Parker and Julliard (2005):

$$
\triangle C_{t+1}^{P-J}=C_{t+3}^{n} / C_{t}^{n}-1, \quad n=T A, T A F .
$$

Third, I calculate fourth-quarter to fourth-quarter consumption (Q4Q4) as in Jagannathan and Wang (2007):

$$
\triangle C_{t+1}^{Q 4 Q 4}=C_{Q 4 ; t+1}^{n} / C_{Q 4 ; t}^{n}-1, \quad n=T A, T A F
$$

where $C_{Q 4 ; t}^{n}=\sum_{m=10}^{12} C_{m ; t}^{n}$. The monthly simulated consumption process is used to calculate the Q4Q4 measure if there is only time aggregation in consumption data $(n=T A)$. For "time aggregated and filtered" consumption $(n=T A F)$, I apply the proportional denton method with the annual filtered level of consumption to benchmark monthly consumption, which results in monthly and quarterly filtered consumption. The proportional denton method is actually used by the BEA to benchmark monthly consumption data on annual consumption data (see BEA (2009) for details).

Simulation Procedure. I simulate the model economy 10,000 times with 792 observations. The first "year" (i.e., the first twelve) observations are needed to calculate annually time aggregated consumption levels for the first year. The next five years of observations are taken as "burn-in" period to calculate filtered consumption. Thus, in each run, 60 years of annual observations on growth rates and returns are included for further analysis.

\section{B Empirical Data}

Consumption. Annual NIPA consumption data is collected from the NIPA tables 2.3.4 / 2.3.5 for "nondurable goods" (Line 8) and "services" (Line 13). The corresponding price indices and the population reported in NIPA table 7.1 (Line 18) are used to compute real per capita growth rates.

NIPA consumption growth data starts in 1930. However, stock market data available on the web site of Kenneth R. French begins in 1927. To not just cut off the stock market crash of 1929 from the sample, I use the consumption measure (including nondurables and services) provided by Robert Shiller on his web site for the period from 1926 to 1929 (which is based on the NBER Kendricks consumption expenditure series), and splice the series with NIPA consumption growth. The NBER Kendricks consumption expenditure series closely follows the measurement methodology used for NIPA consumption. However, there is no consumption measure available for 1926 to 1929 which measures nondurables and services separately. Thus, I assume that the real per capita growth rate for these four years is identical for nondurables and services and splice the series with NIPA nondurables and services and 
NIPA nondurables. Real per capita consumption growth for 1926 is needed to construct the unfiltered NIPA consumption growth of 1927.

Financial Returns. Annual stock market returns are collected from the web site of Kenneth R. French (the market return, and 25 Fama-French portfolios sorted by size and bookto-market). I use the one-year risk-free interest rate provided on the web site of Robert Shiller to calculate the equity premium and excess returns on the 25 Fama-French portfolio returns. Stock market returns are deflated using the inflation rate implied by the consumption measure (NIPA nondurables and services). 


\section{References}

Ait-Sahalia, Y., J. A. Parker, and M. Yogo (2004): "Luxury Goods and the Equity Premium," Journal of Finance, 59, 2959-3004.

Bansal, R., And A. Yaron (2004): "Risks for the Long Run: A Potential Resolution of Asset Pricing Puzzles," Journal of Finance, 59, 1481-1509.

BEA (2009): Concepts and Methods of the U.S. National Income and Product Accounts. The NIPA Handbook, 2009.

Bell, W. R., And D. W. Wilcox (1993): "The Effect of Sampling Error on the Time Series Behavior of Consumption Data," Journal of Econometrics, 55, 235-265.

Breeden, D. T. (1979): "An Intertemporal Asset Pricing Model with Stochastic Consumption and Investment Opportunities," Journal of Financial Economics, 7, 265-296.

Breeden, D. T., M. Gibbons, and R. Litzenberger (1989): "Empirical Tests of the Consumption-oriented CAPM," Journal of Finance, 44, 231-262.

Burnside, C. (2011): "The Forward Rate Premium is Still a Puzzle, a Comment on "The Cross-Section of Foreign Currency Risk Premia and Consumption Growth Risk"," Amercian Economic Review, 101, 3456-3476.

Campbell, J. Y. (2003): "Consumption-based Asset Pricing. In: Constantinides, G., Harris, M., Stulz, R. (Eds)," Handbook of the Economics of Finance, North-Holland, Amsterdam, 803-887.

Campbell, J. Y., A. W. Lo, and A. C. MacKinlay (1997): "The Econometrics of Financial Markets," Princeton University Press, New Jersey.

Cochrane, J. H. (2005): “Asset Pricing," Princeton University Press, New Jersey.

Den HaAn, W. J., And A. T. Levin (2000): "Robust Covariance Matrix Estimation with Data-Dependent VAR Prewhitening Order," NBER Technical Working Paper 255.

Engsted, T., And S. V. Møller (2011): "Cross-sectional Consumption-based Asset Pricing: the Importance of Consumption Timing and the Inclusion of Severe Crises," CREATES Research Paper.

FAma, E. F., AND J. D. MacBeth (1973): "Risk, Return, and Equilibrium: Emprical Tests," Journal of Political Economy, 81, 607-636.

Geltner, D. (1989): "Estimating Real Estate's Systematic Risk from Aggregate Level Appraisal-based Returns," AREUEA Journal, 17, 463-481.

(1993): "Estimating Market Values from Appraised Values without Assuming an Efficient Market," Journal of Real Estate Research, 8, 325-345.

Gregory, A. W., And T. Wirjanto (1993): "Discussion: The Effect of Sampling Error on the Time Series Behavior of Consumption Data," Journal of Econometrics, 55, 267-273. 
Grossman, S. J., A. Melino, And A. Shiller (1987): "Estimating the Continuous-Time Consumption-based Asset Pricing Model," Journal of Business and Economic Statistics, $5,315-327$.

Hall, R. E. (1978): "Stochastic Implications of the Life Cycle-Permanent Income Hypothesis: Theory and Evidence," Journal of Political Economy, 86, 971-987.

(1988): "Intertemporal Substitution in Consumption," Journal of Political Economy, 96, 339-357.

Hansen, L. P., And K. H. Singleton (1982): "Generalized Instrumental Variables Estimation of Nonlinear Rational Expectations Models," Econometrica, 50, 1269-1286.

Hayashi, F., And C. Sims (1983): "Nearly Efficient Estimation of Time Series Models with Predetermined, but not Exogenous Instruments," Econometrica, 51, 783-798.

Jagannathan, R., And Y. Wang (2007): "Lazy Investors, Discretionary Consumption, and the Cross-Section of Stock Returns," Journal of Finance, 62, 1623-1661.

Kalman, R. E. (1960): "A New Approach to Linear Filtering and Prediction Problems," Transactions of the ASME-Journal of Basic Engineering, 82, 35-45.

Lettau, M., And S. C. Ludvigson (2009): "Euler Equation Errors," Review of Economic Dynamics, 12, 255-283.

LuJngqvist, L., And T. J. SARgent (2004): "Recursive Macroeconomic Theory," MIT Press, Cambridge.

LuCAs, R. E. (1978): "Asset Prices in an Exchange Economy," Econometrica, 46, 1429-1445.

Mehra, R., And E. C. Prescott (1985): "The Equity Premium: A Puzzle," Journal of Monetary Economics, 15, 145-161.

Newey, W. K., And K. D. West (1987): "A Simple, Positive Semi-Definite, Heteroskedasticity and Autocorrelation Consistent Covariance Matrix," Econometrica, , 55, 703-708.

PArker, J. A. (2001): "The Consumption Risk of the Stock Market," Brookings Papers on Economic Activity, 2, 279-348.

Parker, J. A., AND C. Julliard (2005): "Consumption Risk and the Cross Section of Expected Returns," Journal of Political Economy, 113, 185-222.

Quan, D. C., And J. M. Quigley (1989): "Inferring an Investment Return Series for Real Estate from Observations on Sales," AREUEA Journal, 17, 218-234.

SAvov, A. (2011): "Asset Pricing with Garbage," Journal of Finance, 66, 177-201.

Shanken, J. (1992): "On the Estimation of Beta-Pricing Models," Review of Financial Studies, 5, 1-33.

TAIO, G. C. (1972): "Asymptotic Behaviour of Temporal Aggregates of Time Series," Biometrika, 59, 525-531.

Tsay, R. S. (2005): "Analysis of Financial Time Series," Wiley-Interscience, New Jersey. 
Weil, P. (1989): "The Equity Premium Puzzle and the Risk-Free Rate Puzzle," Journal of Monetary Economics, 24, 401-422.

Wilcox, D. W. (1992): "The Construction of U.S. Consumption Data: Some Facts and Their Implications for Empirical Work," Amercian Economic Review, 82, 922-941.

Working, H. (1960): "Note on the Correlation of First Differences of Averages in a Random Chain," Econometrica, 28, 916-918. 